\title{
Optical Fibre on a Silicon Chip
}

\author{
A. Michael, C.Y. Kwok, Md. Al Hafiz and Y.W. Xu \\ Additional information is available at the end of the chapter \\ http://dx.doi.org/10.5772/54246
}

\section{Introduction}

Silicon is a typical substrate on which most devices on chip are made. It is a common platform for integrated circuits due to its well understood and established technological processes such as ionic implantation, diffusion, oxidation and others. Silicon has excellent mechanical properties, which make it suitable for realizing sensors and actuators on chip, which are often classified as Micro-Electro-Mechanical Systems. Integrated optics and planar light wave circuits have also extensively employed silicon as a substrate. Currently, silicon-photonics have become a promising technology to increase processing speed and reduce power consumption in multi-core micro-processor architecture.

Whenever optical interface to a silicon chip is required, optical signals must be coupled to optical components on the chip via optical fibres. These optical components include planar optical waveguides, micro-mirrors, photo-detectors, optical-switches, and micro-lenses among others. Precise alignment is necessary to increase the optical coupling. Such precise alignment is enabled by the formation of structures and mechanical components on the chip that positions the core of the fibre at the desired location with sub-micron precision. Silicon micro-machining is the technology that is instrumental for realizing such alignment structures and mechanical components on the chip for optical coupling purposes.

In this section, the various silicon micro-machining technologies available and the fundamental principles behind the technologies will be described. Special emphasis will be given to those which are particularly useful for optical MEMS applications.

\subsection{Silicon micro-machining}

Silicon micro-machining refers to the physical and chemical mechanisms of removing silicon material in a precisely controlled fashion, with the precision going down to a nano-scale. It 
can be achieved through various technologies. These technologies can be broadly categorized as wet and dry etch.

The wet etch can be further classified into isotropic and anisotropic silicon etch. Isotropic etch displays the same etch rate in all directions while anisotropic etch has directional etch rate dependency, which arises from differences in the etching rates of various crystallographic orientations in silicon by certain chemical solutions. For example, 25\% TMAH water solution etches (100) crystal planes at 300 times faster than (111) crystal planes.

Dry etch in silicon is often accomplished by generating RF driven plasma. Positively charged ions and reactive species are created in the plasma. They are responsible for physical and chemical etching effects in dry etch. Although there are also other forms of dry etch that involve ion creation other than plasma, our focus will be on plasma based dry etch. As in the wet etch, dry etch can also be divided into isotropic and anisotropic. Positively charged ion bombardment and polymer deposition from reactive and neutral species are responsible for providing directionality and physical etchings in dry etch. Reaction between reactive species and silicon, on the other hand, yields chemical etching behavior to dry etch. The diagram in Figure 1 summarizes the classifications of silicon micro-machining technologies and commonly used etchants.

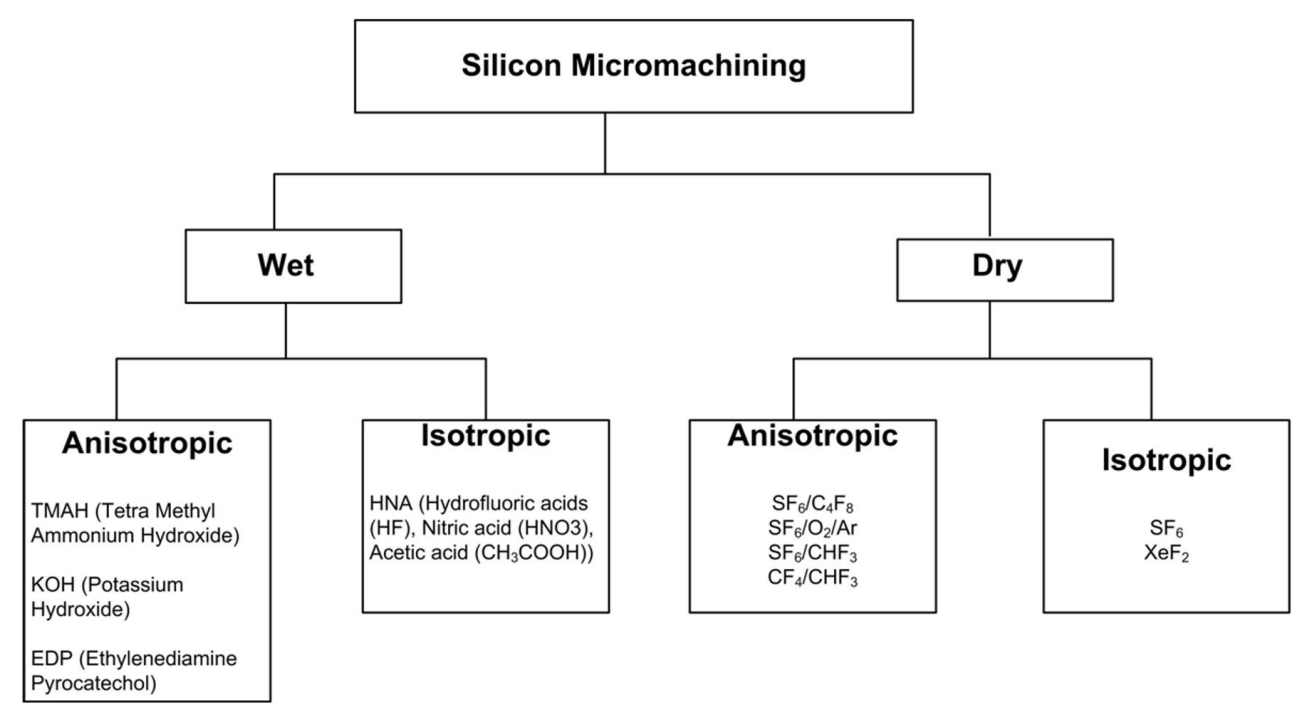

Figure 1. Classification of silicon micromachining 


\subsection{Silicon wet etch}

\subsubsection{Isotropic silicon wet etch}

Acidic solutions containing oxidizing agents are used in an isotropic silicon wet etch. HNA, the solution of $\mathrm{HF}$ (hydrofluoric acid) $/ \mathrm{HNO}_{3}$ (Nitric acid) $/ \mathrm{CH}_{3} \mathrm{COOH}$ (Acetic acid), is typical isotropic silicon and poly-silicon wet etchant. The dissolution of silicon proceeds with injection of holes into valance band of covalently bonded silicon structures. The source of the hole is the oxidizing agent, $\mathrm{HNO}_{3}$, in the solution. The result is oxidation of silicon, which reacts readily with hydroxide ions in the solution to produce $\mathrm{SiO}_{2}$ layer. The resulting $\mathrm{SiO}_{2}$ layer will dissolve in $\mathrm{HF}$ by forming water soluble $\mathrm{H}_{2} \mathrm{SiF}_{6}$. Etching process of silicon in HNA can be summarized by the following simplistic reactions:

$\mathrm{HNO}_{3}+\mathrm{HNO}_{2} \rightarrow 4 \mathrm{NO}^{-}+2 \mathrm{~h}^{+}+\mathrm{H}_{2} \mathrm{O}$ (holes generation)

$\mathrm{Si}+4 \mathrm{~h}^{+} \rightarrow \mathrm{Si}^{4+}$ (holes injection)

$\mathrm{Si}^{4+}+4 \mathrm{OH}^{-} \rightarrow 2 \mathrm{SiO}_{2}+2 \mathrm{H}_{2}$ (silicon oxide formation)

$\mathrm{SiO}_{2}+6 \mathrm{HF} \rightarrow \mathrm{H}_{2} \mathrm{SiF}_{6}+\mathrm{O}_{2}+2 \mathrm{H}_{2}$ (dissolution of silicon-dioxide)

The overall reaction can be simplified to

$\mathrm{Si}+\mathrm{HNO}_{3}+6 \mathrm{HF} \rightarrow \mathrm{H}_{2} \mathrm{SiF}_{6}+\mathrm{HNO}_{2}+\mathrm{H}_{2} \mathrm{O}+\mathrm{H}_{2}$

The role of $\mathrm{CH}_{3} \mathrm{COOH}$ (Acetic acid) in HNA is to dilute the solution. It is preferred to $\mathrm{H}_{2} \mathrm{O}$ as it can better control the dissociation of $\mathrm{HNO}_{3}$, and hence preserve its oxidizing power [1]. Due to the hole injection mechanism, etch rate of silicon in HNA depends on the type and concentration of dopants in silicon. Heavily doped silicon substrates etch faster. The etch rate reduces by 150 times when the concentration of dopants in silicon goes below $10^{17}$ atoms $/ \mathrm{cm}^{3}$ [2]. Table 1 summarizes the etching characteristics of HNA including suitable masking materials.

\begin{tabular}{ll}
\hline Parameter & Characteristics \\
\hline Typical composition & $250 \mathrm{ml} \mathrm{HF}(49.2 \mathrm{wt} \%)+500 \mathrm{ml} \mathrm{HNO}_{3}(69.5 \mathrm{wt} \%)+800 \mathrm{ml} \mathrm{CH}{ }_{3} \mathrm{COOH}[3]$ \\
\hline Etch rate & $4 \mathrm{um} / \mathrm{min}-20 \mathrm{um} / \mathrm{min}$ (at room temperature and increases with agitation) [4] \\
\hline Surface roughness & Rough- with more proportion of $\mathrm{HNO}_{3}$ \\
& Smooth - with more proportion of $\mathrm{HF}[1]$ \\
\hline Temperature dependent & $\begin{array}{l}\text { 10-20Kcal/mol activation energy for concentrated } \mathrm{HNO}_{3}, \text { and } 4 \mathrm{Kcal} / \text { mole for concentrated } \\
\mathrm{HF}[5]\end{array}$ \\
\hline Masking material & Silicon-nitride is the best mask material with only $10^{\circ} \mathrm{A}-100^{\circ} \mathrm{A} / \mathrm{min}$ etches rates in HNA. \\
& Other masking materials include Au/ $\mathrm{Cr}$ at room temperature, and thick thermal oxide. \\
\hline
\end{tabular}

Table 1. Etching characteristics of HNA 
Although isotropic wet etch of silicon has a wide range of application in making micro-needles for drug delivery and micro-probes for scanning microscopy, it is not suitable for formation of optical fiber insertion grooves as it may be difficult to control precisely the etched sizes of the grooves.

\subsubsection{Anisotropic silicon wet etch}

Anisotropic silicon wet etch is based on alkaline solution, which exhibits different etch rates depending on the crystal orientation of the exposed surface. Although there is still disagreement on why such crystallographic dependent phenomenon occurs, there are various models suggested to explain the behavior. These models include: (i) the number of silicon atoms on various crystallographic planes varies, with (111) plane having the largest density. However, such differences between the crystallographic planes do not explain the significant etch rate variations; (ii) The bond between the silicon atoms on the surface and the underlying atoms has different energy levels depending on the orientation of the surface [6]; (iii) the variations in nuclear roughness of various crystallographic planes, with (111) plane having the highest nuclear roughness of all planes [7]. Nuclear roughness is characterized as a nuclear barrier that reduces the etch rate by several dimensions.

Etching of silicon in such crystallographic dependent solutions proceeds with injection of electrons into the conduction band of silicon that results in oxidation of $\mathrm{Si}$ atoms on the surface by the following reaction

$\mathrm{Si}+4 \mathrm{OH} \rightarrow \mathrm{Si}(\mathrm{OH})_{4}+4 \mathrm{e}-$

In the presence of $\mathrm{H}_{2} \mathrm{O}$, the silicate complex will be transformed into hexahydrosilicate complex due to the reduction of hydrogen in the water.

$\mathrm{Si}(\mathrm{OH})_{4}+4 \mathrm{e}-+4 \mathrm{H}_{2} \mathrm{O} \rightarrow \mathrm{Si}(\mathrm{OH})_{6}{ }^{2-}+2 \mathrm{OH}^{-}+2 \mathrm{H}_{2}$

The overall reaction becomes

$\mathrm{Si}+4 \mathrm{H}_{2} \mathrm{O}+2 \mathrm{OH}^{-} \rightarrow \mathrm{Si}(\mathrm{OH})_{6}{ }^{2-+} 2 \mathrm{H}_{2}$

From the overall reaction, one can see that anisotropic wet etch solution requires $\mathrm{OH}^{-}$groups, water solution, and results in the formation of $\mathrm{H}_{2}$ that rises as bubbles. It is also important to note that the etching process is based on the transfer of electrons into the conduction band of the silicon, and as such the etching rate can be controlled by applying bias voltage. In fact, electrochemical etch stop is based on applying bias voltage that effectively stops the transfer of electrons into the silicon conduction bands.

Typically used alkaline solutions and their selectivity between the major crystallographic planes are summarized in Table 2. It will be worthwhile to note that selectivity between major crystallographic planes can vary by changing the composition of the solution and adding additives. Isopropanol and surfactants are commonly used additives in alkaline solutions. Although surfactants are added in order to reduce roughness of the etched surface and formation of hillocks, they are also found to affect etching characteristics of TMAH solutions. Generally, it slows down the etch rate of (110) oriented silicon surface. 


\begin{tabular}{|c|c|c|c|c|c|}
\hline Description & $\mathrm{KOH}$ & TMAH (1) & TMAH (2) & TMAH (3) & EDP \\
\hline Etching solution & $\begin{array}{l}\text { Potassium } \\
\text { Hydroxide (24\%) } \\
\text { water solution, 85 }\end{array}$ & $\begin{array}{l}\text { Tetra Methyl } \\
\text { Ammonium } \\
\text { Hydroxide ( } 25 \%) \\
\text { water, } 90^{\circ} \mathrm{C}\end{array}$ & $\begin{array}{l}\text { Tetra Methyl } \\
\text { Ammonium } \\
\text { Hydroxide } \\
(25 \%) \text { water } \\
\text { with } 0.1 \% \\
\text { surfactants, } \\
60^{\circ} \mathrm{C}\end{array}$ & $\begin{array}{l}\text { Tetra Methyl } \\
\text { Ammonium } \\
\text { Hydroxide } \\
(25 \%) 60^{\circ} \mathrm{C}\end{array}$ & $\begin{array}{l}\text { Ethylendiamin, } \mathrm{NH}_{2}^{-} \\
\left(\mathrm{CH}_{2}\right)_{2}-\mathrm{NH}_{2} \text {, Pyrocatechol } \\
\mathrm{C}_{6} \mathrm{H}_{4}(\mathrm{OH})_{2}\end{array}$ \\
\hline$R(100)$ & $100 \mu \mathrm{m} / \mathrm{hr}$ & $55 \mu \mathrm{m} / \mathrm{hr}$ & $7.2 \mu \mathrm{m} / \mathrm{hr}$ & $7.8 \mu \mathrm{m} / \mathrm{hr}$ & 75 \\
\hline$R(110)$ & - & $65 \mu \mathrm{m} / \mathrm{hr}$ & $2.7 \mu \mathrm{m} / \mathrm{hr}$ & $18 \mu \mathrm{m} / \mathrm{hr}$ & - \\
\hline$R(111)$ & $0.25 \mu \mathrm{m} / \mathrm{hr}$ & $1.4 \mu \mathrm{m} / \mathrm{hr}$ & $0.6 \mu \mathrm{m} / \mathrm{hr}$ & $0.6 \mu \mathrm{m} / \mathrm{hr}$ & 35 \\
\hline Masking layer & $\begin{array}{l}\mathrm{Si}_{3} \mathrm{~N}_{4}(70 \mathrm{~nm} / \mathrm{hr}) \\
\text { Thermal } \mathrm{SiO}_{2} \\
(0.43 \mu \mathrm{m} / \mathrm{min}) \\
{\mathrm{PECVD}-\mathrm{SiO}_{2}} \\
(0.7 \mu \mathrm{m} / \mathrm{min})\end{array}$ & $\begin{array}{l}\mathrm{SiO}_{2}\left(10^{-4} \mathrm{R}(100)\right) \text {, } \\
\mathrm{Si}_{3} \mathrm{~N}_{4}\end{array}$ & $\mathrm{SiO}_{2}, \mathrm{Si}_{3} \mathrm{~N}_{4}$ & $\mathrm{SiO}_{2}, \mathrm{Si}_{3} \mathrm{~N}_{4}$ & $\begin{array}{l}\mathrm{SiO}_{2}(12 \mathrm{~nm}-30 \mathrm{~nm} / \mathrm{hr}), \\
\mathrm{Si}_{3} \mathrm{~N}_{4}(6 \mathrm{~nm} / \mathrm{hr}), \mathrm{Au}, \mathrm{Cr}, \mathrm{Ag}, \\
\mathrm{Cu}\end{array}$ \\
\hline $\begin{array}{l}R(100)\left(P^{++}-\right. \\
S i): R(100)\end{array}$ & $1: 20$ & $1: 40$ & - & - & \\
\hline
\end{tabular}

Table 2. Typical anisotropic wet etching solutions

Three factors play important roles in determining the shape of the volume that will be formed in anisotropic wet etching solution. They are (i) the shape of the mask that determines the exposed pattern of silicon; (ii) the orientation of the mask edges; (iii) crystallographic etching characteristics (etch rate diagram) of the alkaline solutions. The crystallographic etching characteristic (etch rate diagram) is often given in a polar diagram form, where the angle from the reference orientation plane indicates the particular crystallographic direction and the magnitude corresponds to the etch rate. Considering the above three factors, creation of threedimensional structure that results in is a complex process and various soft wares have been developed to assist engineers to perform simulation and prepare the right mask layout. Nonetheless, one can apply Wulff-Jaccodine method [8] along with the following etching behaviors at the convex corner, concave corner, and straight mask edge to make simple constructions of the resulting feature.

- At the straight mask edge: the etching progresses parallel to the mask edge and its shifting represents the etching-off of a side wall.

- At the Concave corners: sidewalls with the lowest etch rate are formed

- At the Convex corners: sidewalls with the maximum etch rate are formed

There are five important etching behaviors that worth discussing due to their significant application in creating grooves for optical fibre insertions, vertical micro-mirrors and sidewalls, and $45^{\circ}$ micro-mirrors. 
1. Formation of V-grooves

The first requirement in the formation of V-grooves is to use (100) oriented silicon substrate. (100) oriented silicon substrate has its primary flat cut in $\langle 110\rangle$ direction. The second requirement is to align square or rectangular window openings on the mask, as illustrated in Figure 2(a), along $<110>$ direction which is parallel to the primary flat. The third requirement is to use anisotropic etchant with etching rate diagram showing minima at $\{111\}$ planes. Etching with the above three requirements fullfilled will result in the formation of Vgrooves (see Figure. 2(b)) or pyramidal pit bounded by (111) planes that are at $54.7^{\circ}$ from (100) surface plane.

Let us now design the window opening size, $w_{0}$, of the mask that is required to form a Vgroove to precisely position the core of an optical fibre at a distance, $R$, from the surface. Figure.2(c) illustrates optical fibre positioned in the V-groove and all the relevant dimensions including the depth of the V-groove from the surface, $d_{e^{\prime}}$ the radius of optical fibre including the cladding ( the standard size is $125 \mu \mathrm{m}$ in diameter), and the position of the core from the surface, $R$. It should be noted that $R$ will be negative if the core is positioned below the surface. The depth of the V-groove from the surface, $d_{e^{\prime}}$ is related to the radius of the optical fibre and the position of the core, $R$ as

$$
d_{e}=108.2-R
$$

It can also be related to the window opening size, $w_{0}$, and lateral under-etching of (111) plane, $t_{u}$, which is of course minimal, as

$$
d_{e}=\tan (54.7)\left(\frac{w_{o}}{2}+t_{u}\right)
$$

Eq. (1) and (2) can be combined and the window opening size can be expressed

$$
w_{o}=2\left(\frac{108.2-R}{\tan (54.7)}-t_{u}\right)
$$

The lateral under-etching of (111) plane, $t_{u}$, can be determined from the etching rate of (111) plane, $R_{(111)}$, and the etch time, $t$.

$$
t_{u}=\frac{R_{(111)} t}{\sin (54.7)}
$$

From Eq.(3), and (4), the window opening size can be simplified to

$$
w_{0}=153.2-1.416 R-2.45 R_{(111)} t
$$

where the etch time should be carried out for at least etching duration of, $t$, given the etch rate of the (100) plane is $R_{(100)}$ 


$$
t \geq \frac{108.2-R}{R_{(100)}}
$$

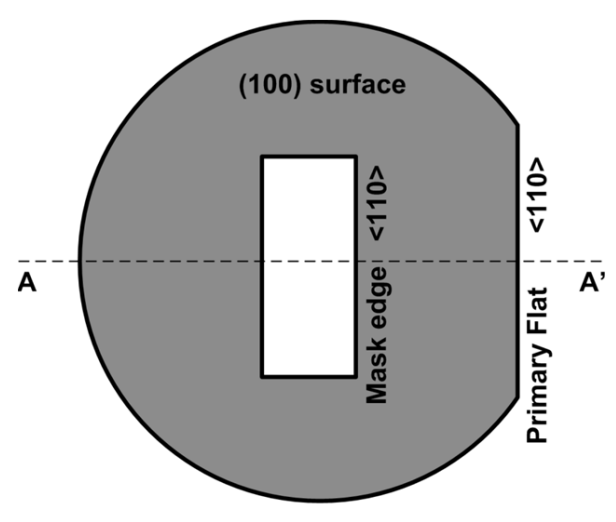

(a)
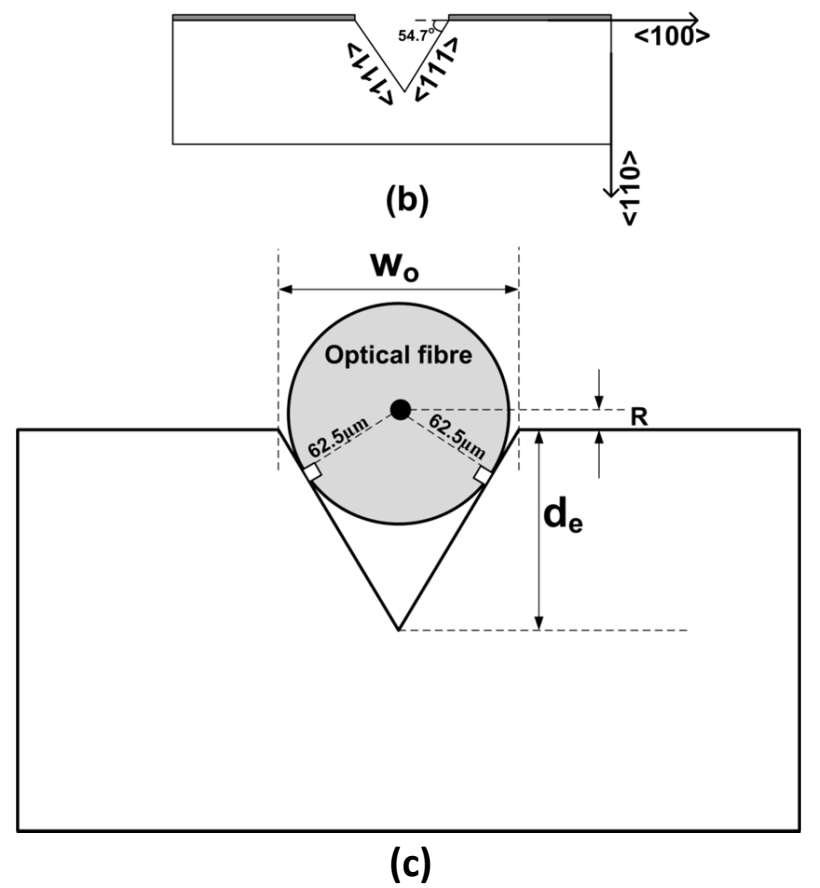

Figure 2. (a) Mask alignment in (100) type silicon; (b) the resulting V-groove after wet anisotropic etch; (c) optical fiber inserted in the $\mathrm{V}$-groove 


\section{Formation of U-grooves}

In this case, (110) type wafer will be used. (110) silicon substrate can be cut with primary flat in $<111>$ direction. This direction can be used as a rough guide to align the window opening. However, for precise alignment of the mask in $<111>$ direction, other techniques of locating the exact $<111>$ direction should be employed. One of these techniques is to incorporate a wagon-wheel mask which extends from $-3^{\circ}$ to $3^{\circ}$ with a pitch of $0.1^{\circ}$. The direction which displays the smallest lateral under-etch indicates the exact location of $<111>$ direction. The (111) planes intersect on (110) surface to each other to form a parallelogram with $109.3^{\circ}$ obtuse and $72.7^{\circ}$ acute angles. The planes are either perpendicular or form $35.6^{\circ}$ with the (110) surface. With etching solution that shows high (110) and (100) etch rates with respect to very slowly etching (111) planes, it is possible to make U-grooves with (111) vertical sidewalls. The same principle has also been applied to make vertical (111) micro-mirrors.

The primary flat of (110) wafer in $<111>$ direction, the parallelogram window opening mask aligned to $<111>$ direction, and the U-groove formed after etching are illustrated in Figure 3(a) and (b). Designing the window size opening for positioning the core of an optical fiber at a desired position in this case is easier than the case before. The depth of U-groove from the surface, $d_{e}$, is related to the radius of the optical fibre and the position of the core, Ras

$$
d_{e}=62.5-R
$$

The window opening size can be expressed

$$
w_{o}=2\left(62.5-t_{u}\right)
$$

The lateral under-etching of (111) plane, $t_{u}$, can be determined from the etching rate of (111) plane, $R_{(111)}$, and etch time, $t$.

$$
t_{u}=R_{(111)} t
$$

From Eq.(8), and (9), the window opening size can be simplified to

$$
w_{o}=125-2 R_{(111)} t
$$

While Eq.(10) determines the required window opening size, the location of core is controlled with etch time, $t$

$$
t \geq \frac{62.5-R}{R_{(110)}}
$$

\section{Formation of rhombus channels}

The etching characteristic, mask alignment direction, and wafer types needed for this purpose are similar to that of the formation of V-grooves, which is discussed earlier. In this case, the Vgrooves are etched sideways in horizontal direction (as shown in Figure. 4(a)) as opposed to 


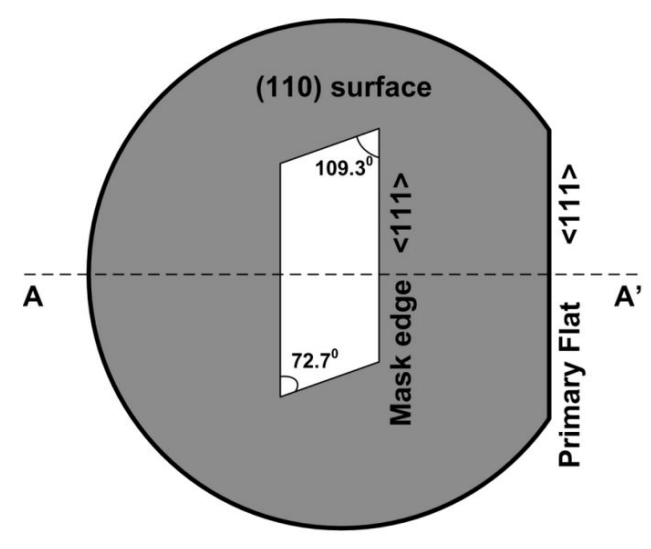

(a)

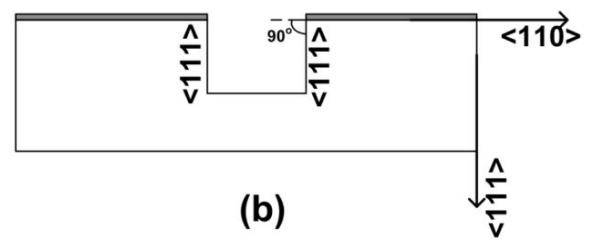

Figure 3. (a) Mask alignment for (110) type wafer with primary flat in (111) direction; (b) the resulting vertical trench after wet anisotropic etch

the previous case, where the V-grooves are etched down in the vertical direction. A narrow vertical opening is first made to expose (100) oriented vertical sidewalls by deep reactive ion etching of silicon as illustrated in Figure 4(b). The exposed vertical (100) silicon surfaces will be etched into a rhombus channels in anisotropic wet etch with sides being in (111). Hoffmann et al [9] has used $20 \% \mathrm{KOH}$ solution at $60^{\circ}$ to form the rhombus channels. Such channels are preferred to other grooves such as $\mathrm{V}$ or $\mathrm{U}$-shaped ones because they provide self-clamping mechanism to the fiber inserted into the position. In $\mathrm{V}$ or $\mathrm{U}$ shaped grooves, other clamping or gluing mechanism will be required to keep the fiber in the required position.

Considering a narrow vertical opening with width, $\omega$, and depth, $d$, before wet anisotropic etch, the final size of the rhombus channel after the wet etch is desired to precisely position the optical fiber as shown in Figure 4(c). The minimum depth, $d$, is related to the width, $\omega$, and the optical fibre radius, $r$ as [9]

$$
d=\frac{2 r}{\cos (\alpha)}-\omega \tan (\alpha)=2 r \sqrt{3}-\sqrt{2} \omega
$$

For (100) silicon, $\alpha=54.7^{\circ}$. 
With the optical fiber of the diameter of $125 \mu \mathrm{m}$, and it is completely buried under the wafer, the minimum depth has to be $125 \mu \mathrm{m}$ and hence the width of the opening at the top should be $64.5 \mu \mathrm{m}$. This is smaller compared to the width openings $241 \mu \mathrm{m}$ for V-grooves and $125 \mu \mathrm{m}$ for U-grooves.

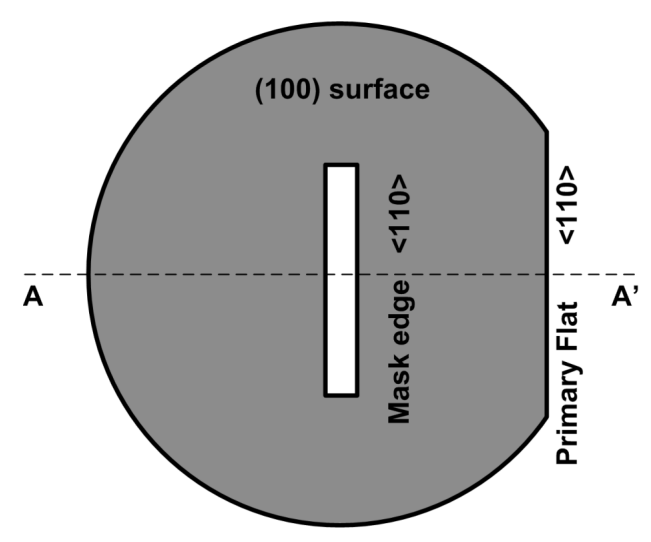

(a)
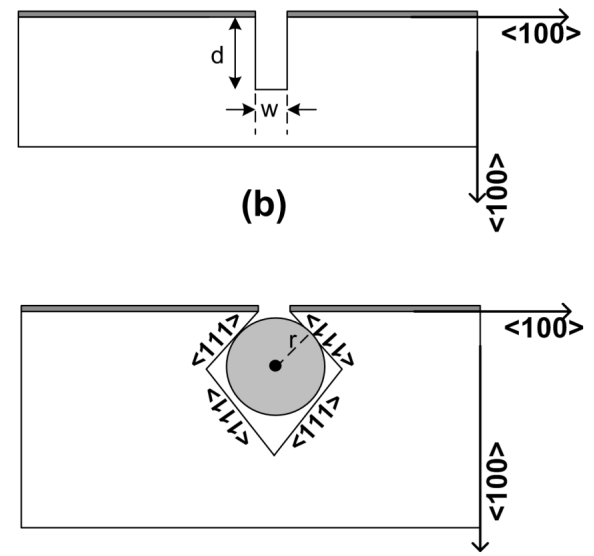

(C)

Figure 4. (a) Mask alignment in (100) type wafer for forming rhombus channels; (b) DRIE of narrow vertical trench in silicon defined by the mask; (c) the rhombus channel made after wet anisotropic etch with optical fiber inserted

4. Formation of vertical (100) micro-mirrors or sidewalls

Vertical mirrors that can precisely be aligned with optical fibers inserted into V-grooves are desired for MEMS based optical switches as it enables self-aligned switching architecture. 
Although such optical switching architectures are possible with dry etching techniques, anisotropic wet etch is preferred due to the better mirror surface quality that is resulted.

For this case, (100) silicon wafer should be employed. The edge of the mask is aligned along $<100>$ direction which is $45^{\circ}$ rotated from the orientation of the primary flat. With etching characteristics, where (110) planes are etching faster than (100) planes, vertical sidewall of (100) planes emerge as the etching progresses, and these planes etch sideways at the same rate as the horizontal (100) planes. With time controlled strategy, it is possible to form (100) vertical micro-mirror of the desired thickness. Such kind of etching behavior has been observed with $\mathrm{KOH}$ solutions [12]. However, TMAH and HNZ have not shown such etching characteristics.

\section{Formation of $45^{\circ}$ micro-mirrors}

The requirement to form such mirror is to use (100) silicon wafer, and align the edge of the mask at $45^{\circ}$ off the primary flat. This is similar to the case where vertical (100) micro-mirror is formed. The difference lies on the etching characteristics of the anisotropic wet etchant. In this case, the etching characteristics should display slower etching rate for (110) plane as compared to all other exposed planes between (100) and (110) planes. Other consideration that needs to be taken into account is the smoothness quality of the resulting surface. It is not easy to find the right etchant composition to satisfy both the requirements: (i) etching characteristics and (ii) surface smoothness. Solutions with the desired etching characteristics (etch diagrams) have displayed a rough $45^{\circ}$ surface. On the other hand, those with smooth surface quality tend to provide inferior etching characteristics. The resulting etched surface becomes more curved than slanted $45^{\circ}$ surface. As a compromise solution and in order to achieve both the requirements, techniques involving multi-step etching have been proposed and demonstrated to provide significant improvement. The first technique [10] involves the use of etching solution with the desired etching characteristics (etch diagrams) as the first step and the use of etching solution with smooth surface quality as the second step. In this technique, the first etching step provides the desired $45^{\circ}$ slope and the second etching step smoothens the rough surface resulted from the first etching step. The end result is slanted $45^{\circ}$ slope with smooth surface. The other technique [11] involves the use of etching solution that provides smooth surface and applying successive removals of suspended oxide mask. This method has improved the $45^{\circ}$ degree portions of the curved mirror by straighten up the top portion.

Table 3 reviews some of the anisotropic wet etchant solutions that have been used by various authors in forming V- grooves, U-grooves, rhombus channels, Vertical and $45^{\circ}$ micro-mirrors.

\subsubsection{Silicon dry etch}

\subsubsection{Isotropic silicon dry etch}

An isotropic dry etch of silicon involves etching of silicon using chemical reactive species that are in vapor form. Various forms of mechanism are employed to form chemical reactive vapor species. They include sublimation of solid sources at low pressure [17], laser assisted etching [18], and plasma [19]. Although all these methods have been proved to be useful, plasma based dry etching process has been a common and standard practice. 


\begin{tabular}{|c|c|c|c|c|c|}
\hline $\begin{array}{l}\text { Optical fibre } \\
\text { insertion, alig } \\
\text { structures, an } \\
\text { micro-mirrors }\end{array}$ & V-groove & U-groove & $\begin{array}{l}\text { Rhombus- } \\
\text { Channels }\end{array}$ & Vertical mirror & $45^{\circ}$ micro-mirror \\
\hline \multirow[t]{6}{*}{ Wet etch } & $33 \% \mathrm{KOH}[12]$ & $25 \%$ TMAH & $20 \% \mathrm{KOH}[9]$ & 25\% TMAH[14] & $5 \%$ TMAH \\
\hline & $\mathrm{KOH}[13]$ & [14] & & $33 \% \mathrm{KOH}[12]$ & $1 \%$ Surfactant [11] \\
\hline & $20 \% \mathrm{KOH}[15]$ & & & $20 \% \mathrm{KOH}[15]$ & 25\%TMAH 0.1\% \\
\hline & & & & & surfactant[10] \\
\hline & & & & & $36 \% \mathrm{KOH}$ \\
\hline & & & & & IIPA( isoproponal)[16] \\
\hline
\end{tabular}

Table 3. Anisotropic wet etching solution for forming optical MEMS

Hecht et al [20 ] and Hoffman et al [21 ] have used Xenon difluoride $\left(\mathrm{XeF}_{2}\right)$ to etch silicon isotropically and release CMOS circuitry, and form sensors and actuators. They produced vapour form of $\mathrm{XeF}_{2}$ by sublimating solid Xenon difluoride at 1 torr and room temperature in a simple bell-jar setup. The etchant has shown excellent selectivity with respect to CMOS process layers. The etching process proceeds with spontaneous reaction of $\mathrm{XeF}_{2}$ with solid $\mathrm{Si}$ to generate volatile gaseous by products of $\mathrm{SiF}_{4}$ and $\mathrm{Xe}$. Etching rates of $1-3 \mu \mathrm{m} / \mathrm{min}$ are typical with $\mathrm{XeF}_{2}$. The disadvantage of $\mathrm{XeF}_{2}$ etch is that it causes rough surface. As a remedy to reduce roughness of the etched silicon, $\mathrm{XeF}_{2}$ has been mixed with other halogen fluoride such as $\mathrm{BrF}_{3}$ and $\mathrm{ClF}_{3}[22]$.

The other common dry etching of silicon in isotropic manner is based on generation of fluorine reactive species from RF plasma. Fluorine, unlike chlorine and bromine, reacts with silicon to produce volatile $\mathrm{SiF}_{4}$ spontaneously. In the absence of polymer deposition, fluorine reactive species from RF plasma produce pure isotropic etch. $\mathrm{SF}_{6}$ is the typical source gas used for this purpose.

Although isotropic dry etches are important to release sensors, actuators, and CMOS circuitry, their applications in forming alignment grooves for inserting optical fibers in silicon are very limited.

\subsubsection{Anisotropic silicon dry etch}

Plasma driven dry etch process can be made directional by controlling ionic energy bombardment and allowing fluorocarbon polymer deposition. Ionic energy bombardment is controlled by the DC bias voltage between the plasma and electrode. Polymer deposition may be allowed by introducing carbon containing gases into the recipe. Directionality of ionic bombardment along with polymer deposition provides anisotropic plasma based silicon etching characteristics. For etching deep and high aspect ratio silicon structures, special reactive ion etching systems are commonly employed. These systems are often referred as Deep Reactive Ion Etchers. Such systems are capable of generating large density of reactive species (plasma), and controlling ionic energy bombardment independent of ionic density. They can also allow the 
substrate to be maintained at cryogenic temperature as low as 77K. At this cryogenic temperature, films can also be deposited from condensations of reactive gases. Sidewall deposition prevents sidewall etching while vertical ionic bombardment removes films deposited on horizontal surface, and allows directional etch [23,24].

Other deep silicon etch is based on alternate etching and deposition steps [25]. The etching step may use $\mathrm{SF}_{6}, \mathrm{SF}_{6} / \mathrm{O}_{2}, \mathrm{SF}_{6} / \mathrm{Ar}$ and can be purely isotropic. After a short time of pure etching, pure deposition step will follow. The deposition step will often use fluorocarbon gases such as $\mathrm{C}_{2} \mathrm{~F}_{8}$ or $\mathrm{CHF}_{3}$. $\left(\mathrm{CF}_{2}\right)_{\mathrm{n}}$ polymers are deposited on the substrate during this step. When these etching and deposition steps are repeated, they yield vertically etched structures.

Deep reactive ion etching of silicon is a very versatile micromachining technique which does not rely on crystalline orientation or type of silicon substrate. It has been used to form Ugrooves for fiber insertion and alignment. Spring structures can easily be integrated with the U-grooves to provide fiber holding mechanism. Ji et al [26] and Marxer et al [27] have used this powerful technique in their 2X2 optical switch architecture. The actuator, micro-mirror, and fiber insertion and alignment grooves are all made in a single mask.

\section{Thick silica film deposition}

In addition to micro-machining techniques for silicon substrate, formation of optical components on silicon chip will require deposition and micro-machining of optical quality films. One of such films is silicon-dioxide (silica). Silica planar waveguides have been for a decade a key platform for fabrication of photonics circuits and optical Micro-Electro-Mechanical Systems (MEMS) devices. They can be easily coupled to optical fibre due to their low index contrast. Fabrication of silica waveguide requires deposition of silica film and consequently micromachining the film to the desired waveguide core size. The thickness of silica for such purpose is usually in the range of $6 \mu \mathrm{m}-8 \mu \mathrm{m}$ depending on the wavelength of the light for which the waveguide is designed. Such thick silica films have to be deposited using chemical vapor deposition techniques. When their integration with integrated circuits is considered, chemical vapor deposition need to be carried out to maintain low thermal budget. In such case, plasma enhanced chemical vapor deposition is an appropriate technique. Moreover, it provides an efficient method of controlling film stoichiometry, refractive index, and surface roughness.

Plasma enhanced chemical vapor deposition of silica film based on the reaction of $\mathrm{SiH}_{4}$ and $\mathrm{O}_{2}$ gaseous has been reported to produce low loss silica waveguides [28,29] although other mixtures of gaseous can be used to deposit silica films. Controlling refractive index of silica film is essential to enable the formation of core and cladding of the waveguide. Silica film has been doped with $\mathrm{Ge}$ by introducing $\mathrm{GeH}_{4}$ into the gaseous mixture, and the refractive index of the silica film has been controlled by varying the doping level of Ge in the silica film [30]. Silica films can also be doped with fluorine to change their refractive index [28,29,31,32]. In this case, $\mathrm{CF}_{4}$ will be introduced as the source of fluorine to the gaseous mixture of $\mathrm{SiH}_{4}$ and $\mathrm{O}_{2}$. Another important parameter of the film that is critical for deposition of thick silica film is stress in the film. The stress should be minimized not only to maintain structural integrity of 
the deposited film but also to avoid stress related birefringence leading to polarization dependence losses. Controlling the stress of Ge-doped silica film has been found difficult [30]. From such perspective, F-doped silica films are preferred ways of minimizing stress and researches have been directed toward achieving this. Bazylenko et al. [28 ] has reported the experimental results of characterization pure and F-doped silica films using Hollow Cathode PECVD system for fabrication of silica waveguides. Their results have shown that fluorine incorporation into silica film reduces both stress and refractive index. However, this trend of stress and refractive index reduction does not continue as more $\mathrm{CF}_{4}$ is introduced into the mixture, but reverses trend and causes more abrupt increase of stress and refractive index. The reason is attributed to the scavenging of $\mathrm{O}_{2}$ by $\mathrm{CF}_{4}$ to cause silicon rich film. Increasing the flow rate of $\mathrm{O}_{2}$ has been suggested as a way of mitigating the scarcity of $\mathrm{O}_{2}$ in the plasma. However, stress in the film increases as more oxygen is added into the plasma at the same flow rate of $\mathrm{CF}_{4}$. Moreover, it does not stop the occurrence of reversal trend at higher $\mathrm{CF}_{4}$ flow rate. The characteristics of F-doped silica films deposited at various RF powers and $\mathrm{O}_{2} / \mathrm{CF}_{4} / \mathrm{SiH}_{4}$ flow rates in HC-PECVD have been studied [31]. Figure.5 shows the refractive index and stress of silica films as the RF power varies from $100 \mathrm{~W}-300 \mathrm{~W}$. The results in the figure are obtained for the flow rates of $\mathrm{CF}_{4}=30 \mathrm{sccm}, \mathrm{O}_{2}=50 \mathrm{sccm}$, and $\mathrm{SiH}_{4}=20 \mathrm{sccm}$. The stress in the silica film reduces as the RF power increases up to $220 \mathrm{~W}$. From $220 \mathrm{~W}$ onwards, the stress starts to increase rapidly. XPS analysis of the films has revealed that the stress reversal behavior at 220W attributes to the onset of oxygen depletion in the plasma and hence silicon richness of the film. As the flow rate of $\mathrm{CF}_{4}$ is reduced maintaining the same flow rates of $\mathrm{SiH}_{4}$ and $\mathrm{O}_{2}$, the $\mathrm{RF}$ power, at which the onset of oxygen depletion occurs, increases markedly. On the other hand, for higher $\mathrm{CF}_{4}$ flow rates, the RF power, at which the onset of oxygen depletion occurs, reduces only slightly. For instance, the increase in $\mathrm{CF}_{4}$ flow rates from $30 \mathrm{sccm}$ to $46 \mathrm{sccm}$ has reduced the required RF power for oxygen deficiency slightly by only $4 \mathrm{~W}$. The RF power, required for onset of oxygen deficiency in the plasma, for various $\mathrm{CF}_{4}$ flow rates has been obtained and plotted in Figure 6. The results clearly indicates that for a given $\mathrm{SiH}_{4}$ and $\mathrm{O}_{2}$ flow rates, there is a threshold RF power below which oxygen depletion in plasma will not occur even at practically higher $\mathrm{CF}_{4}$ flow rates. This means that continuous reduction in silica film stress as well as refractive index can be achieved with incorporation of more fluorine into the film. It is even possible to deposit oxide film with slightly tensile stress at higher $\mathrm{CF}_{4}$ flow rates. This is particularly useful to reduce the overall stress in thick film deposition [33] and to form MEMS structures that are not prone to buckling [34].

It has been indicated before that it is possible to shift the occurrence of oxygen depletion in the plasma to a higher $\mathrm{CF}_{4}$ flow rate by increasing oxygen flow rate in the gaseous mixture. This is an obvious solution as more oxygen will be available in the plasma, and causes oxygen rich film. However, the film becomes more stressed. In order to reduce the stress in the film while increasing permissible $\mathrm{CF}_{4}$ flow rate range in which oxygen depletion does not occur, $\mathrm{SiH}_{4}$ flow rate is reduced. This has lowered the silicon content of the silica film and less stressed film results [31]. Figure 7 (a) and (b) show stress and refractive index of silica film deposited at various $\mathrm{CF}_{4}$ flow rates at $300 \mathrm{~W}$ RF power and $\mathrm{O}_{2}=100 \mathrm{sccm}$ for $\mathrm{SiH}_{4}=20 \mathrm{sccm}$ and $\mathrm{SiH}_{4}=$ $15 \mathrm{sccm}$, respectively. 


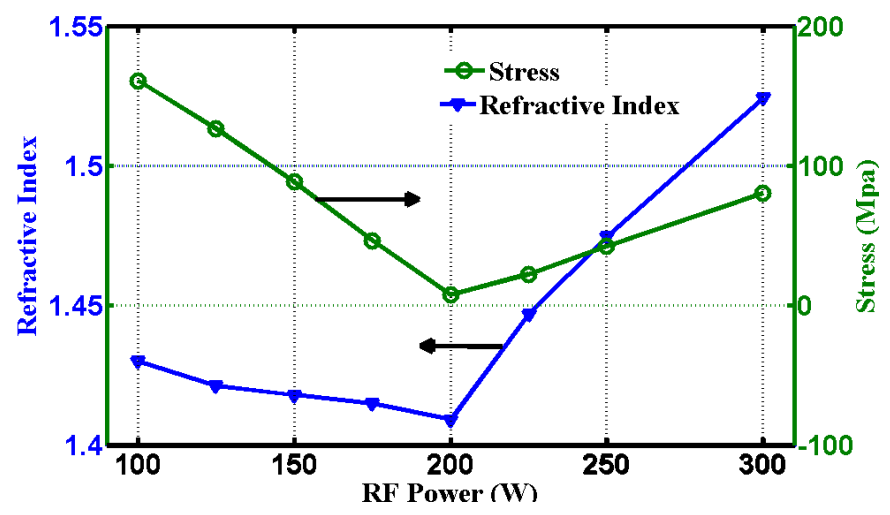

Figure 5. Refractive index (green) and stress (blue) as a function of RF powers

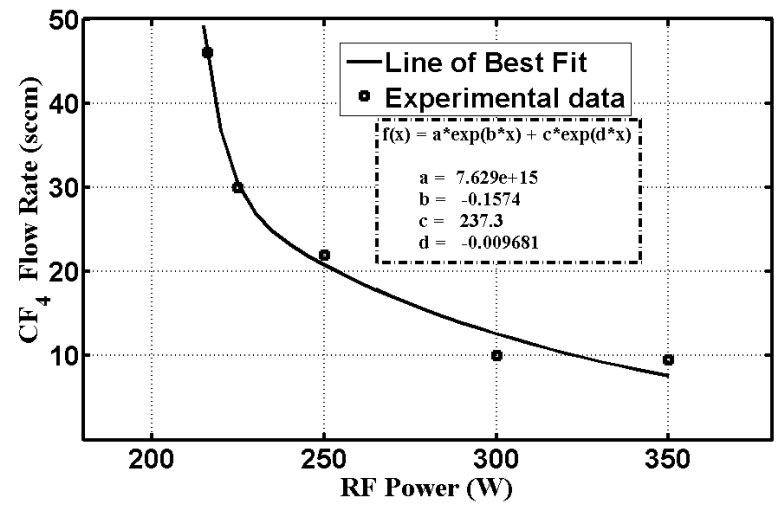

Figure 6. RF powers and $\mathrm{CF}_{4}$ flow rates at which oxygen depletion starts to occur

Depositing a desired film thickness is based on characterizing deposition rate the given deposition condition. Measuring deposition rates of silica films at various $\mathrm{CF}_{4}$ flow rates have shown that deposition rates are almost constant independent of $\mathrm{CF}_{4}$ flow rates [31,32]. This behavior is quite attractive for depositing F-doped graded index layers for making planar waveguides and planar grin lenses. Figure 9 shows the constant deposition rate of silica film at $\mathrm{RF}$ power $=300 \mathrm{~W}, \mathrm{O}_{2}=100 \mathrm{sccm}$ and $\mathrm{SiH}_{4}=15 \mathrm{sccm}$ for various $\mathrm{CF}_{4}$ flow rates.

The above deposition techniques have been used to form silica films as thick as $90 \mu \mathrm{m}$ as shown in Figure 8. Such successful thick film deposition is attributed to the reduction of stress in the film to almost zero. This is useful characteristics for realizing optical components on silicon chip including planar silica waveguides, planar silica lens and 3D micro-lens. 


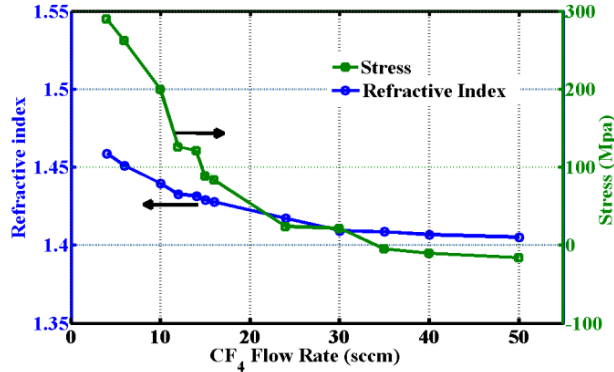

(a)

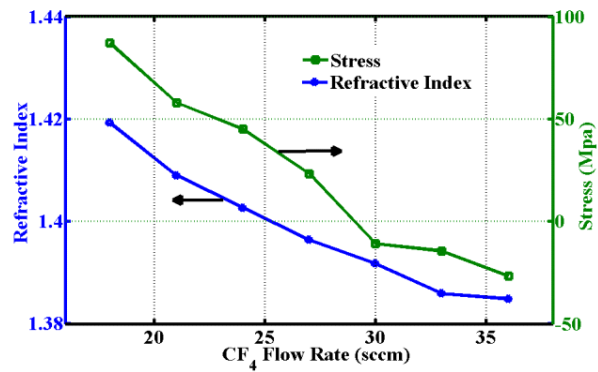

(b)

Figure 7. Refractive index and stress for various flow rates at (a) $\mathrm{SiH}_{4}=20 \mathrm{sccm}$ (b) $\mathrm{SiH}_{4}=15 \mathrm{sccm}$

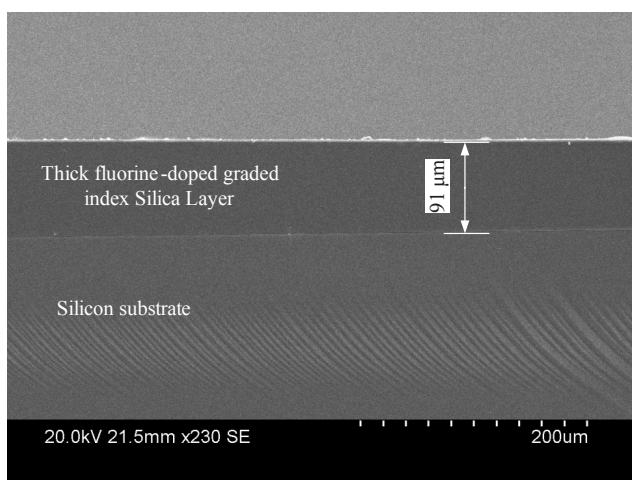

Figure 8. SEM cross-sectional view of thick fluorine-doped graded index silica layer deposited by HC-PECVD deposited on a plane silicon substrate;

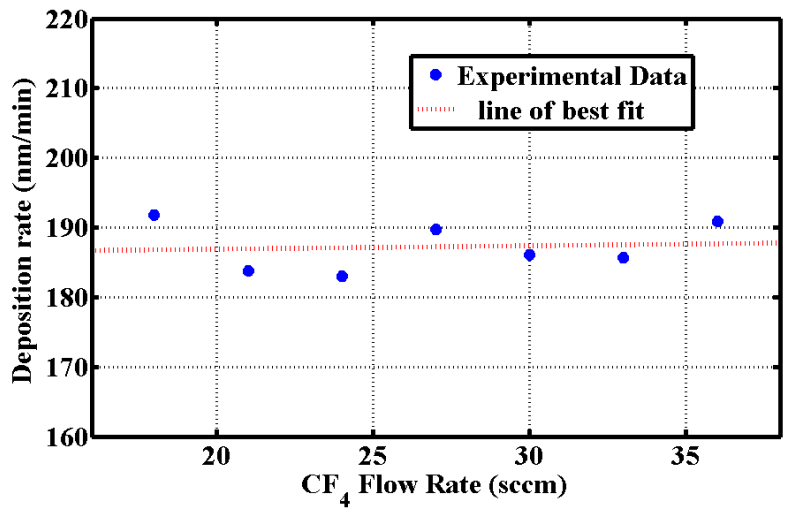

Figure 9. Deposition rate as a function of CF4 flow rates 
By depositing silica films with parabollically graded refractive index profile, planar silica lens can be fabricated $[32,35]$. The desired graded index profile as a function of thickness is represented by step wise approximation. An index step of 0.001 has been found to minimize optical loss due to the approximation to only $0.5 \mathrm{~dB}$ [30]. The step index of 0.001 or less is, therefore, often chosen for step-wise approximation of the desired refractive index profile. Based on the chosen step index, the corresponding step height at a desired thickness can be computed from the refractive index profile. The refractive index value at the desired height corresponds to a unique $\mathrm{CF}_{4}$ flow rate (depending on other deposition conditions such as Figure 7(a) or (b)), and the step height corresponds to deposition duration (based on deposition rates) for the constant and corresponding $\mathrm{CF}_{4}$ flow rate. Thus, the desired refractive index profile can be translated into a deposition schedule which indicates what $\mathrm{CF}_{4}$ flow rate to use, for how long and when. The $\mathrm{CF}_{4}$ flow rate at the scheduled time determines the refractive index. How long the $\mathrm{CF}_{4}$ is maintained at the scheduled time determines the step height at the desired thickness, which is related to the scheduled time.

It is important to confirm that the deposition schedule has resulted in the desired parabolic graded index profile. This is done by confirming experimentally the periodic refocusing characteristic of the graded index profile. To measure the periodic refocusing length, first spin Polymer poly (N-vinylpyrrolidone) (PVP) doped with Xanthene dye, Phloxine B, on top of the deposited graded index layer. A green light from a single mode fiber coupled to a frequency doubled Nd:YAG laser (532 nm) source can then be shined onto the graded index silica side of cleaved sample. The resulting periodic yellow emissions due to the excitation of the dye from the extension of the evanescent field into the polymer layer can be measured to determine periodic refocusing length.

\section{Silica micro-machining}

In addition to the ability to deposit thick and refractive index modulated silica layers, capability of micro-machining thick silica film is also necessary to form micro-optical components on silicon substrate. Vertical and relatively smooth sidewalls are desired in most situations. Reactive ion etching is capable of providing such etching characteristics. Unlike silicon, reactive ion etching of silica is a more aggressive process as there are no gaseous species that react with silicon-dioxide spontaneously. Some level of reactive ion bombardment and fluorocarbon polymer film deposition are needed. The fluorocarbon film reacts with silica in the presence of ion bombardment to form a volatile $\mathrm{SiF}_{4}$. To increase the etch rate of silica and improve mask selectivity, the ionic current density, ionic energy, and $\mathrm{F} / \mathrm{C}$ reactive ion species are required not only to be boosted [36 ] but also independently controlled. Inductively coupled plasma (ICP) reactive ion etching system can fulfill these requirements. The substrate potential with respect to the plasma can be independently controlled by the platen RF power. High density plasma, controlled by the RF coil power, can be generated at low pressure to result in the desired ionic current density. Advanced Oxide Etch STS ICP has been used to etch thick silica and glass layers using various masks [37]. Photoresist masks are acceptable when the etch depth of less than $6 \mu \mathrm{m}$ are required. For deeper etches in a range of $6 \mu \mathrm{m}-50 \mu \mathrm{m}$, polysilicon 
masks are more appropriate. When the etch depth of greater than $50 \mu \mathrm{m}$ is desired, metal masks should be used. We have done thick silica film etching using amorphous silicon as a mask in Advanced Oxide Etch STS-ICP (AOE STS-ICP) system. The etching experiments are discussed below.

Amorphous silicon film is deposited onto a thick silica layer using HC-PECVD system as an etch mask for deep silica etch. Mixture of $\mathrm{SiH}_{4}$ and Ar gases at $4 \mathrm{mtorr}$ chamber pressure and 300W RF power are employed as process parameters for depositing amorphous silicon film. Photoresist is spun on amorphous silicon film and photo lithographically patterned. Figure 10(a) shows the cross-sectional view of the patterned photoresist on the top of the amorphous silicon film. Using the photoresist as the mask, the amorphous silicon film is dry-etched. $\mathrm{SF}_{6}$ and $\mathrm{C}_{4} \mathrm{~F}_{8}$ chemistry at $20 \mathrm{mtorr}$ chamber pressure and $600 \mathrm{~W}$ (RF coil power)/30W (RF platen power) are used to etch the amorphous silicon at $1 \mu \mathrm{m} / \mathrm{min}$ and expose the silica in AOE STSICP. Figure 10(b) is the cross-sectional SEM images of the patterned amorphous layers on the top of thick silica.

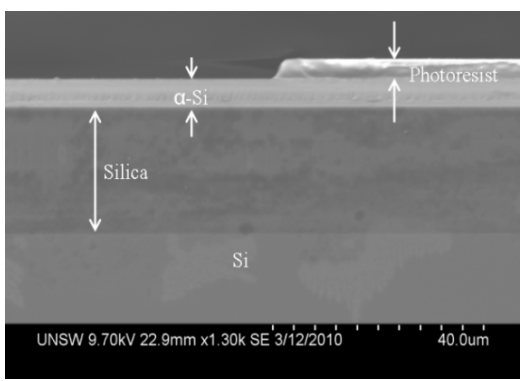

(a)

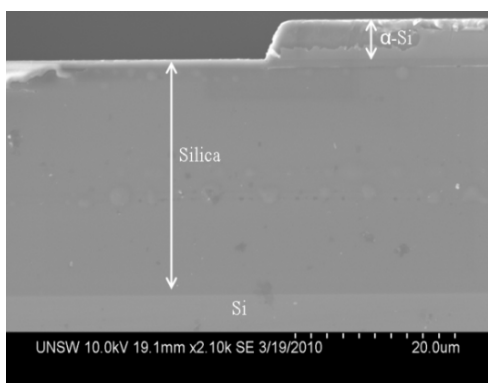

(b)

Figure 10. Cross-sectional image of patterned (a) photoresist on the top of amorphous silicon (b) amorphous silicon on the top of thick silica

Various recipes have been investigated to etch thick silica. The recipes are based on varying the coil and platen powers while keeping other parameters constant. $\mathrm{C}_{4} \mathrm{~F}_{8}$ (at $\left.30 \mathrm{sccm}\right)$ and $\mathrm{He}$ (at $300 \mathrm{sccm}$ ) are used as the process gases at $6 \mathrm{mtorr}$ chamber pressure. The coil powers of $1000 \mathrm{~W}, 1400 \mathrm{~W}$, and $1800 \mathrm{~W}$ and platen powers of 200W, 400W and 500W have been investigated to optimize the etching process for achieving vertical side wall, high selectivity between silica and amorphous silicon, and high etching rate. Figure 11 (a) and (b) plot the etch rate, selectivity between the silica and amorphous silicon layer, and sidewall angle as a function of coil powers with $400 \mathrm{~W}$ platen power, and as a function of platen power with $1000 \mathrm{~W}$ coil power, respectively. The results indicate that the etch rate, selectivity, and sidewall angle are improved by increasing platen power at a given coil power or vice versa. Large coil and platen power, however, have caused the receding of the mask. The mask receding increases proportionally with coil and platen power and is attributed most likely to the fast erosion of the mask at the corner edges due to the concentration of electric field at those spots. In order to avoid such mask receding and achieve the desired etching profile (vertical sidewall and fast etch rate), 


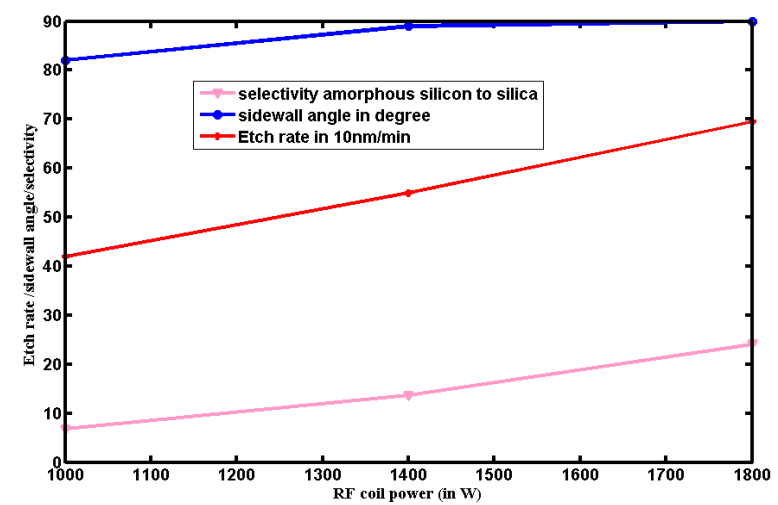

(a)

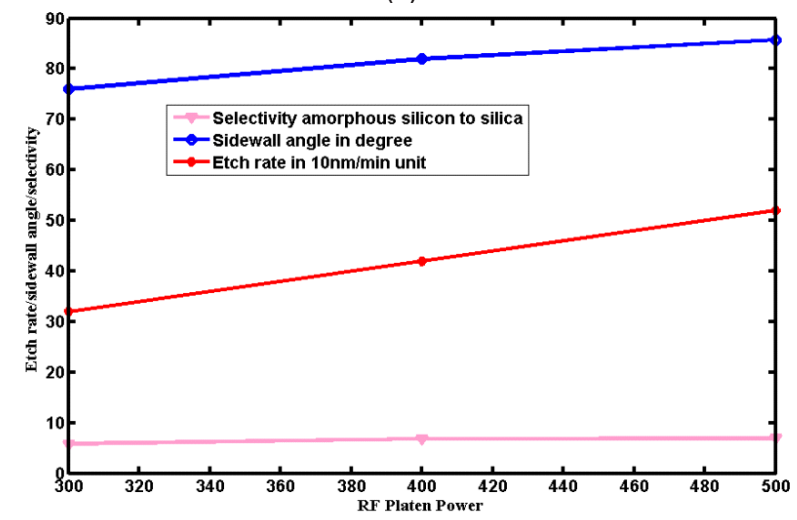

(b)

Figure 11. Etch rate, selectivity, and sidewall angle for (a) various RF coil power with $400 \mathrm{~W}$ platen power (b) various RF platen power with 1000W RF coil power.

coil RF power of $1400 \mathrm{~W}$ and platen RF power of $400 \mathrm{~W}$ have been chosen as best compromising process parameters. Figure 12 shows the SEM image of the cross-sectional view of the etched silica layer at the chosen process parameter. Vertical and relatively smooth sidewall has been achieved.

\section{Planar silica lens pairs}

Before we look at some applications of silicon and silica micro-machining in optical switching and optical interconnects, it is important to first present planar silica lens pair. This is because of the significant applications that this planar ens pair has for optical switching and interconnect. Hence, the design principles and fabrication of the planar lens pair will be described in this section. 


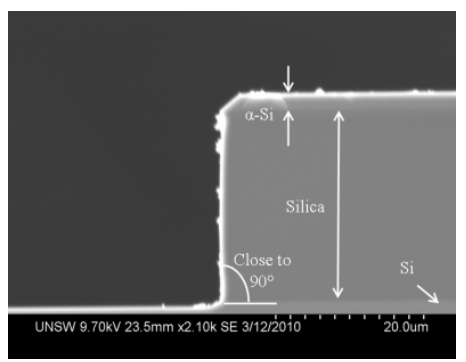

Figure 12. Cross-sectional SEM image of deep etched silica film using the optimized etching recipe

Optical beam will be required to propagate in free space from one planar silica waveguide to another in Planar Light wave Circuits (PLC). Free Space optical switch and interconnect systems are based on such requirements. The design of such systems should ensure the propagation loss be minimized. The free space propagation loss between two planar waveguides depends on the optical beam size, propagation distance, and misalignment ( both lateral and angular) between the waveguides. These losses have been well understood and the behaviors can be summarized as follows

- The propagation loss increases with propagation distance.

- The propagation loss increases with lateral and angular misalignments.

- The propagation loss increases as the beam spot size reduces. Such losses are significant even for small propagation distances, in a range of $10 \mu \mathrm{m}-100 \mu \mathrm{m}$, for the spot sizes of typical silica waveguides, in a range of $2 \mu \mathrm{m}-6 \mu \mathrm{m}$.

Significant free-space propagation loss at smaller spot size attributes to the large divergence angle of the optical beam. Such large divergence angle associated with smaller optical beam size can be reduced by collimating the optical beam at the source and re-focusing the beam back to the original beam size at the receiving end. Although traditional 3D lens can do the collimation and re-focusing, it will be difficult to integrate them with planar waveguides. Therefore, planar lens pairs are needed for planar waveguides.

Planar lens pairs with parabolically graded index profile in a vertical direction and convex curvature in horizontal direction have been proposed [30]. The design of such lens has been discussed in detail [30, 35, 38 ]. Here, the design flow chart will be presented to illustrate the design methodology. Relevant articles and associated equations are referred in the flow chart to direct interested readers for more detailed information.

The schematic of the planar lens pair with design parameters is shown in Figure 13(a), in which, $d T$ is the free-space propagation distance, $\omega_{0}$ is the input spot-size of the Gaussian beam. The graded index profile of silica, defined by $n(x)=\left\{n_{0} 2\left[1-2 \Delta(x / \rho)^{2}\right]\right\}^{1 / 2}$, is used for the design of micro-lens pair, where $\Delta=\left(n_{0}^{2}-n_{c l}^{2}\right) / 2 n_{0}^{2}$ is the relative index change, and $x$ is the transverse (vertical) coordinate. $n_{0}, n_{c l}$ and $\rho$ are the maximum refractive index, minimum refractive index 
and half-width of the graded index profile, respectively. Other system parameters required for the planar lens pair design, but not shown in Figure 13(a), are the maximum refractive index in the graded index profile, $n_{0}$, the relative index change, $\Delta$, the vertical spot-size $\omega c x$, at mid-point of the free-space propagation distance and the wavelength $\lambda$. The evolution of the Gaussian input spot-size as it propagates through the micro-lens pair and the free-space in between is illustrated schematically in Figure 13 (b) and (c). Figure 14 shows the flow chart of a planar lens pair design procedure for an ideal free-space propagation distance, $d T$, with zero loss. Design parameters are taken as inputs to the design flow. Other parameters that will be calculated during the planar lens pair design include (i) horizontal spot-size at the micro-lens/ air interface, wiy, (ii) horizontal spot-size at mid-point of the free-space propagation distance, $\omega c y$, (iii) maximum vertical spot-size in the micro-lens section, $\omega m x$, (iv) radius of curvature defining the convex shape, $R$, (v) planar lens length, $L$, (vi) focusing parameter, $\alpha=\sqrt{2 \Delta} / \rho$, (vii) minimum refractive index of the graded index profile, $n_{c l}$, and (viii) half-width of the parabolic graded index profile, $\rho$.

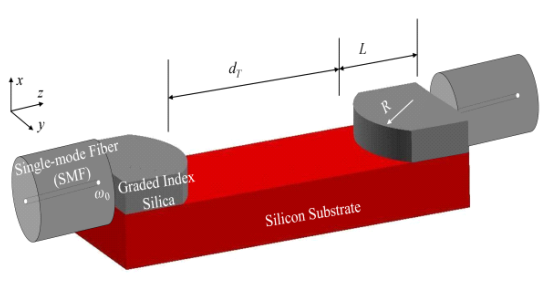

(a)

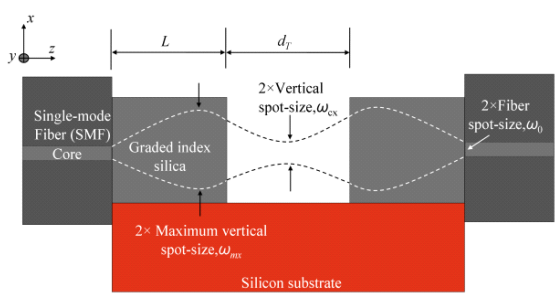

(b)

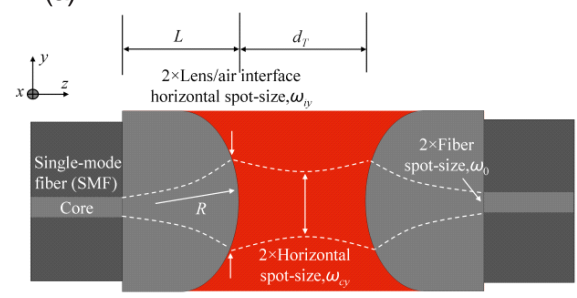

(c)

Figure 13. (a) Schematic of a planar silica planar lens pair with input and output fibre, (b) side view, and (c) top view, showing the Gaussian beam evolution in the micro-lens pair and in the free-space.

At the beginning of the design flow, the design parameters, $\lambda, n_{0}, \omega_{0}, \omega c x, d T / 2$ and $\Delta$ are used to find the ABCD parameters [38] in the vertical direction. The outputs of this stage are planar lens length $L$ and the half-width of the parabolic refractive index profile $\rho$. Using the value of $\rho$, the length of one fourth of the ray period, $\pi \rho / 4 \sqrt{2 \Delta}$, is calculated where the vertical beam diameter reaches its maximum value. The maximum vertical beam spot-size $\omega m x$ is then computed. At this stage of design flow, a decision has to be made as to whether the vertical beam spot-size is sufficiently small or not because this parameter determines the thickness of the graded index film to be deposited for the planar lens fabrication. If the decision is ' $\mathrm{No}^{\text {', the }}$ 
design process will go back to the input stage to change the vertical spot-size at mid-point of the free-space propagation distance $\omega c x$. Otherwise, the design flow will continue to the next step to find the lens/air interface horizontal spot-size wiy, from which the horizontal spot-size at mid-point of the free-space propagation distance $\omega c y$, is obtained. Using $L, n_{0}, \lambda, \omega c y, \omega_{0}$ and $d T / 2$ together with wiy and $\omega c y$, the ABCD parameters in the horizontal direction are calculated. Finally, the radius of curvature of the planar lens front-face $R$, is determined from the $\mathrm{ABCD}$ parameters in the horizontal direction [38].

Based on the design flow chart and design parameters indicated in Table 4(a), planar lens pairs for $d T=200 \mu \mathrm{m}$ is designed. The calculated parameters for the planar lens pair are provided in Table 4(b).

\begin{tabular}{cc}
\hline & $\boldsymbol{d}_{T}=\mathbf{2 0 0} \boldsymbol{\mu m}$ \\
\hline Design parameters & Value \\
\hline$\Delta$ & $0.633 \mu \mathrm{m}$ \\
\hline$n_{0}$ & 0.01 \\
\hline$\omega_{0}$ & 1.40 \\
\hline$\omega_{c x}$ & $2.1 \mu \mathrm{m}$ \\
\hline
\end{tabular}

(a)

\begin{tabular}{cc}
\hline & $\boldsymbol{d}_{\boldsymbol{T}}=\mathbf{2 0 0 \mu \boldsymbol { m }}$ \\
\hline Calculated parameter & Value \\
\hline$\omega_{\text {iy }}$ & $12.67 \mu \mathrm{m}$ \\
\hline$\omega_{c y}$ & $12.57 \mu \mathrm{m}$ \\
\hline$\omega_{m x}$ & $6.69 \mu \mathrm{m}$ \\
\hline$R$ & $52.45 \mu \mathrm{m}$ \\
\hline$L$ & $182.36 \mu \mathrm{m}$ \\
\hline$a=\sqrt{2 \Delta} / \rho$ & $10.24 \times 10^{-3} \mu \mathrm{m}-1$ \\
$\mathrm{ncl}$ & 1.386 \\
$\rho$ & $13.8 \mu \mathrm{m}$ \\
\hline
\end{tabular}

(b)

Table 4. (a) Design parameters and (b) Calculated parameters for the micro-lens pairs designed for $d_{T}=200 \mu \mathrm{m}$. 


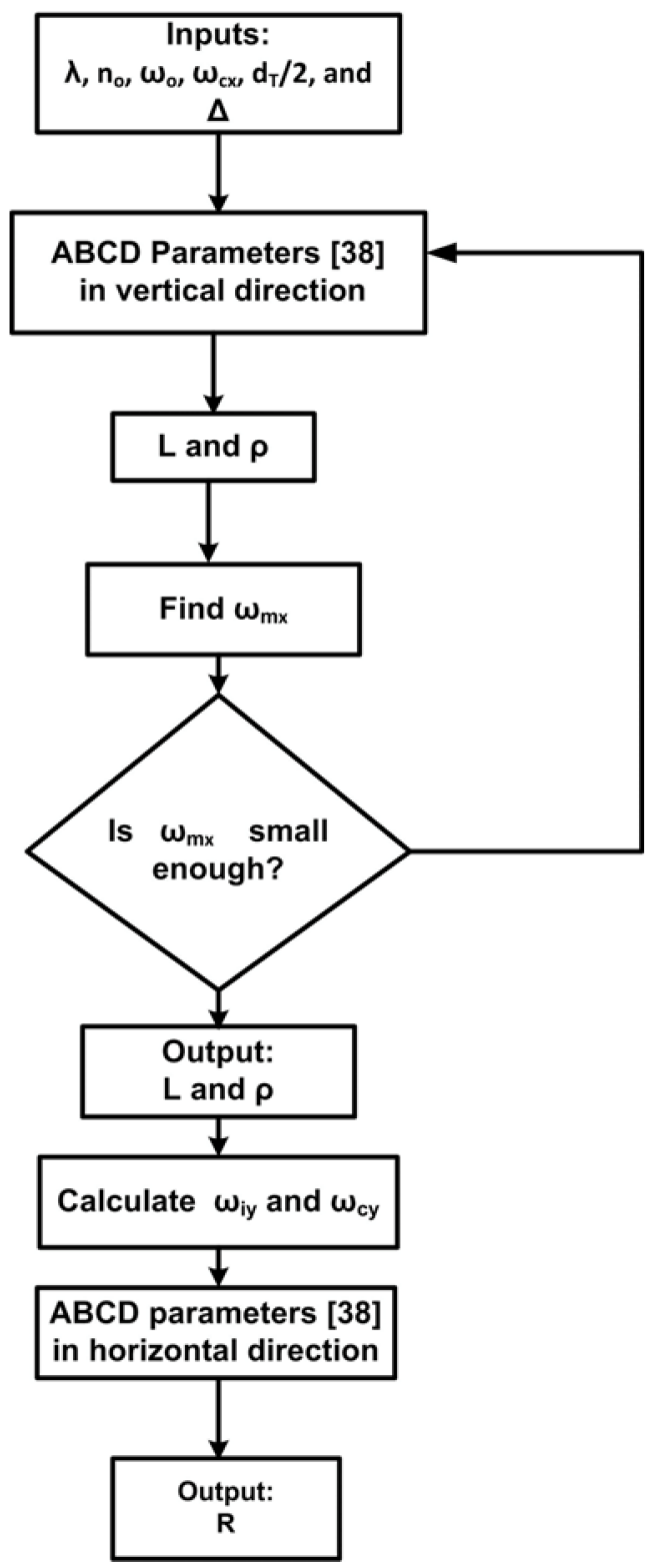

Figure 14. Design flow chart.

It can be shown from the design methodology of the planar silica lens that as the design parameter, $\mathrm{d}_{T}$, free-space propagation distance increases the required thickness of the lens increases provided that other design parameters are kept the same. For example, for $d_{T}=500$ 
$\mu \mathrm{m}$, the required thickness of the silica planar lens almost doubles. The thickness of the planar lens pairs for $\mathrm{d}_{\mathrm{T}}=200 \mu \mathrm{m}$ is $2^{*} \omega_{m x}+$ buffer layer $(6 \mu \mathrm{m})+$ capping layer $\left.(4 \mu \mathrm{m})\right)$ whereas for $\mathrm{d}_{\mathrm{T}}=500 \mu \mathrm{m}$, the thickness has to increase to $32 \mu \mathrm{m}$. The implication is that deposition of low stress thick silica film and its micro-machining will be necessary to create low loss long free-space optical link on chip. It also signifies the importance of deposition and micro-machining techniques discussed earlier.

The planar lens pairs designed for $\mathrm{d}_{\mathrm{T}}=200 \mu \mathrm{m}$ have been fabricated and tested to substantiate the design [35]. The SEM image of the planar lens pairs with V-grooves for optical fiber insertion and alignment is shown in Figure 15. The fabrication process steps consists of thick graded silica film deposition, silica micro-machining, and wet anisotropic etching of silicon using TMAH. The process starts with (100) silicon wafer. The graded index silica film with buffer and capping layers is then deposited on the silicon wafer according to the deposition schedule obtained from the step-wise approximation of the parabolic graded index profile designed for $\mathrm{d}_{\mathrm{T}}=200 \mu \mathrm{m}$. An amorphous silicon layer is deposited on the top of the thick silica layer and patterned. Using the patterned amorphous silicon as a mask, the thick silica layer is etched to define the convex curvature of the lens, the free space distance between the lens pairs, and openings on silicon for forming the V-grooves. Finally, the sample is etched in $25 \%$ TMAH with $0.1 \%$ of surfactants to form the $\mathrm{V}$ - grooves and the free space between the lens pairs. Figure 16 illustrates the fabrication process steps.

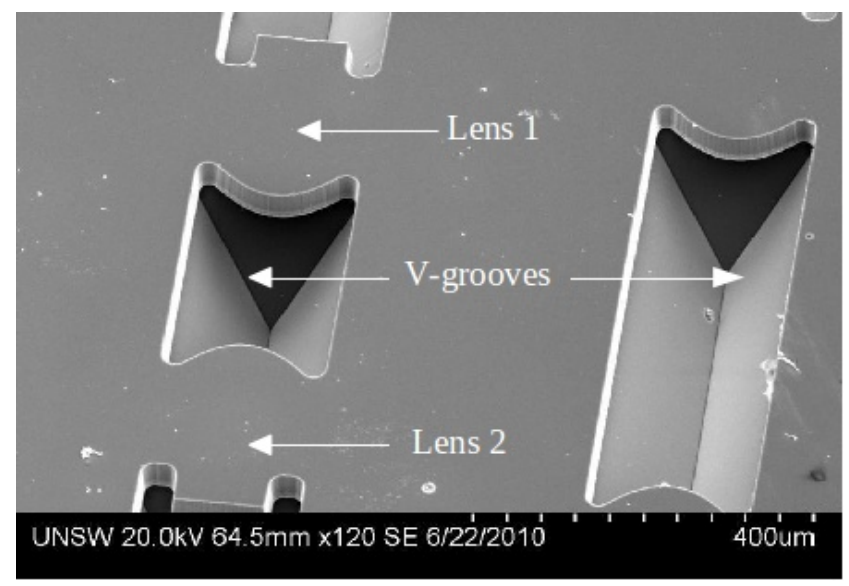

Figure 15. The SEM image of fabricated micro-lens pairs with V-grooves

After fabrication, the input and output optical fibers are inserted into the V-grooves and butt coupled to the planar lens pair. A 633nm optical signal from a pigtailed laser source is coupled to the input fiber while the output optical power at the output optical fibre is measured. The power at the output of the input fiber is measured to be used as a reference power to calculate the optical loss in the system. 


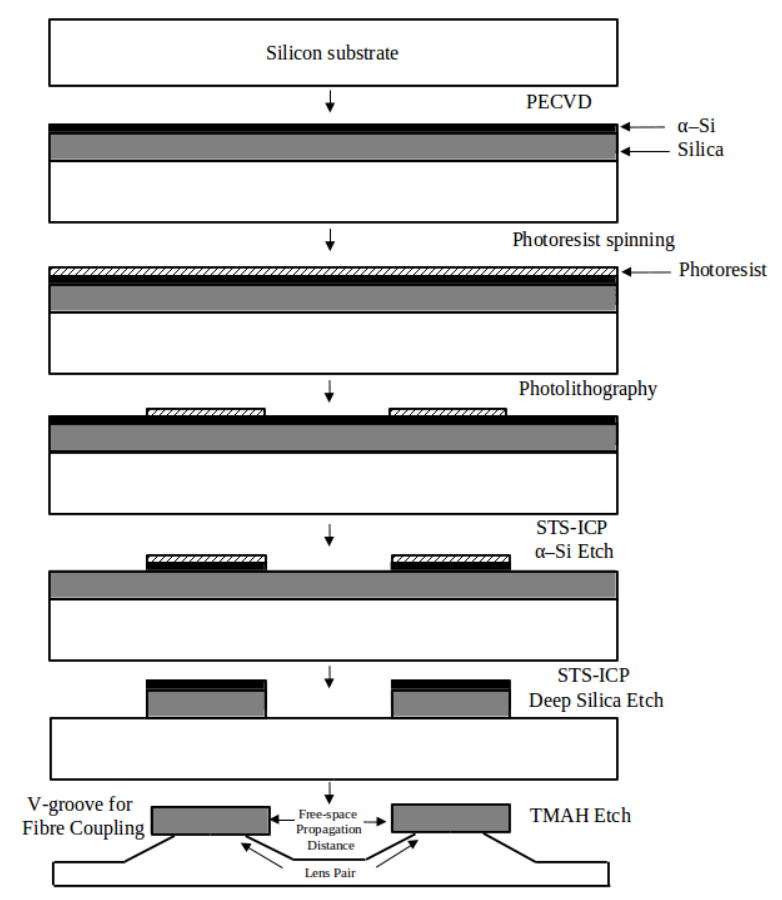

Figure 16. Fabrication process flow.

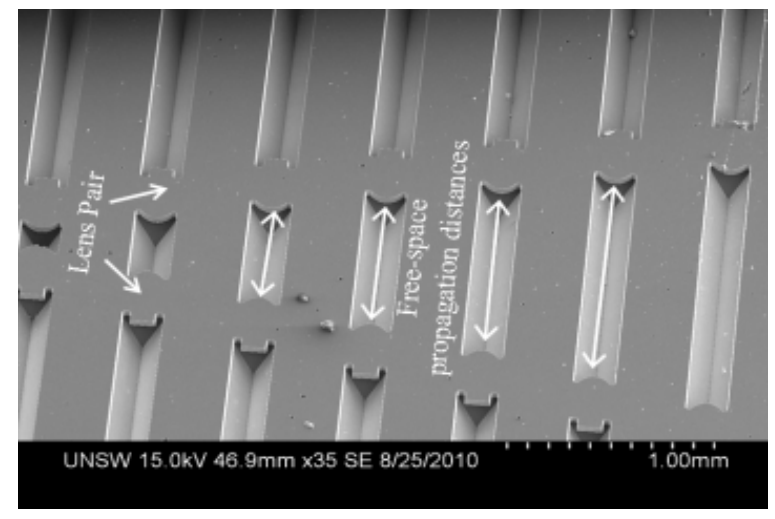

Figure 17. SEM image of identical micro-lens pairs with various free-space propagation distances

To evaluate the performance of the planar lens pair, various free-space propagation distances were fabricated, apart from the ideal free-space propagation distance of $200 \mu \mathrm{m}$ as shown in Figure 17. The measured and theoretically calculated losses for the planar lens pairs are plotted in Figure 18 for free-space propagation distances of 50, 100, 200, 300, 400 and $500 \mu \mathrm{m}$. 


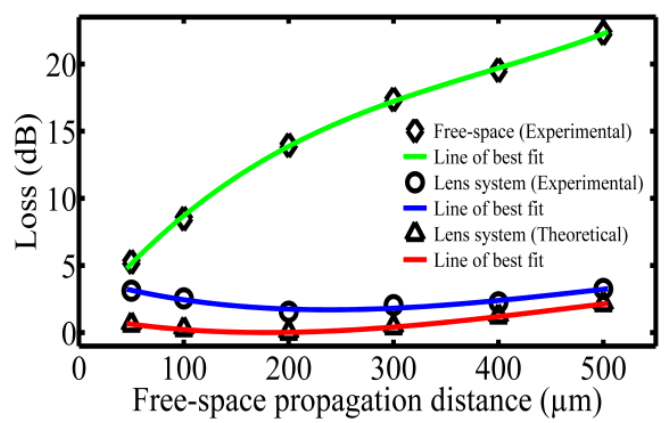

Figure 18. Free-space propagation losses with and without the micro-lens pair set ups designed for $d_{T}=200 \mu \mathrm{m}$.

The measurement indicates that there is a good agreement between the theoretical calculations and experimental results. It can also be seen that the planar lens pair is best suited for $200 \mu \mathrm{m}$ free-space propagation distance, for which it is designed, and the increase in loss from the minimum is only about $1 \mathrm{~dB}$ for $\pm 50 \%$ departure from the optimal free-space distance of 200 $\mu \mathrm{m}$.

Loss reduction in using the planar lens pair in free-space propagation distances in comparison to the case without the lens pair is also plotted in Figure 18. The coupling loss for $200 \mu \mathrm{m}$ freespace propagation distance is measured to be $13.95 \mathrm{~dB}$ whereas by using the planar lens pair the loss is reduced to $1.56 \mathrm{~dB}$, which is $12.4 \mathrm{~dB}$ reductions in loss. For longer free-space propagation distances, the loss improvement is even more significant. For example, $19 \mathrm{~dB}$ of measured reduction in loss is obtained for $500 \mu \mathrm{m}$ of free-space distance using the micro-lens pair designed for $200 \mu \mathrm{m}$. This is particularly significant as it compares to a theoretical $21 \mathrm{~dB}$ loss improvement expected for a micro-lens pair designed for an ideal zero loss free-space propagation distance of $500 \mu \mathrm{m}$.

The application of this planar lens pairs for optical switching and interconnects in a free-space can be significant as it can be used to collimate light for waveguides integrated on the chip, and optical fibers coupled to the integrated circuits. The applications of planar lens in MEMS based optical switch architectures and 3D optical interconnect systems will be described.

\section{Applications}

\subsection{MEMS based optical switching}

MEMS based optical switches have been described extensively in the literature. The following are some characteristic advantages that make MEMS especially suitable for optical switching applications compared to other optical switching mechanisms such as those based on change in the refractive index due electro-optic, thermo-optic, acoustic-optic, or free carrier effects [39-42] and bubble switches [43-45]. 
- Low insertion loss and cross talk

- Independent of optical wavelength, polarization and data modulation.

- small size

- Reliability

- Mass-production at low cost

- Enable large matrix switching to be monolithically integrated in a single chip

The continuing increase in the high speed transfer of large data size using the internet and large increase in the WDM channel count have led to the increased demand for compact and multi-channel optical switches. MEMS technology has been proposed as a means of meeting these requirements. As a result, many new developments have been reported in MEMS optical switches. In fact, it is evolved into a new field of MEMS called MOEMS (Micro- Opto-ElectroMechanical Structures).

MEMS optical switches are generally classified as 3-D MEMS optical switches and 2-D MEMS optical switches. In 3-D MEMS optical switches [46, 47], micro-mirrors are rotated into two axes to steer optical beam in any desired direction. Because the mirrors can assume any possible positions, they are also referred as 'Analog optical switches'. On the other hand, in 2-D MEMS optical switches, the micro-mirrors assume only two-positions and move into or out of the optical beam direction. As a result of assuming only two positions, they are called 'Digital optical switches'.

\subsubsection{D MEMS optical switch}

The 2D MEMS optical OXC architecture uses a dedicated mirror to cross connect an input port to a particular output port. The mirror is manipulated by an actuator to assume one of two positions. When it is in one position, it establishes a connection by directing light from an input port to an output port. In another position, it moves out of the optical path and ends the connection. 2-D MEMS switches have been commonly implemented using two approaches: free-space and guided-wave. Free-space approaches are characterized by the presence of fairly long, typically larger than $200 \mu \mathrm{m}$, free space travel and optical fibers as waveguides. On the other hand, guided-wave approaches are characterized by a short free space propagation distance and the presence of planar wave guides instead of optical fibers. However, the coupling of the planar waveguides with optical fibers is required to interface optical signals from off-chip sources. This is especially the case for telecommunication application where optical fibers are signal carriers.

\subsubsection{MEMS Actuators for 2-D MEMS Free space optical switches}

Various MEMS actuators are used in 2-D MEMS free space optical switches. These actuators include Scratch Drive Actuators (SDA) [48, 49], Cantilever, Comb-drive, Torsion Beam, Hinged Plates and Bridges. 
Lin et al $[50,51]$ have used arrays of SDAs to make flip-up mirrors for optical switching applications as shown in Figure 19 (a) and (b). Lee et al[52] and Chen et al[53] used SDAs to create self assembly mechanism for their optical switching system. SDAs were also employed to drive a cam-micromotor for optical fiber switching by Kanamori et al [54] as shown in Figure 19 (c) and (d). Although SDAs are in-plane actuator, not intrinsically bi-stable and move only in one direction, it is possible to create bi-stable, two-way actuated, outof-plane optical switches by using interleaved micro-hinges, pushrods and two sets of SDAs such as the one developed by Lin et al[50]. The only disadvantage of SDAs is that they require large voltage for operation, typically larger than $100 \mathrm{~V}$.

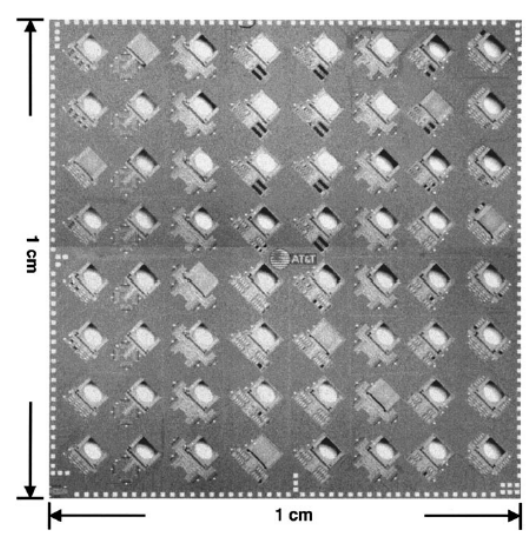

(a)

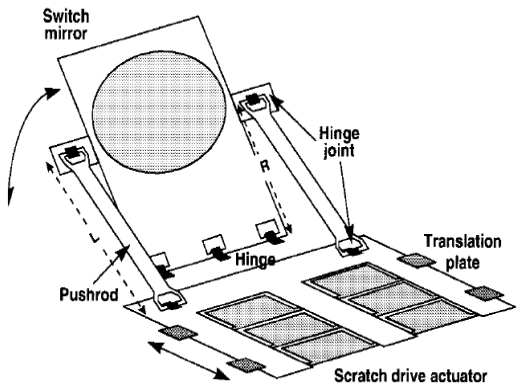

(b)

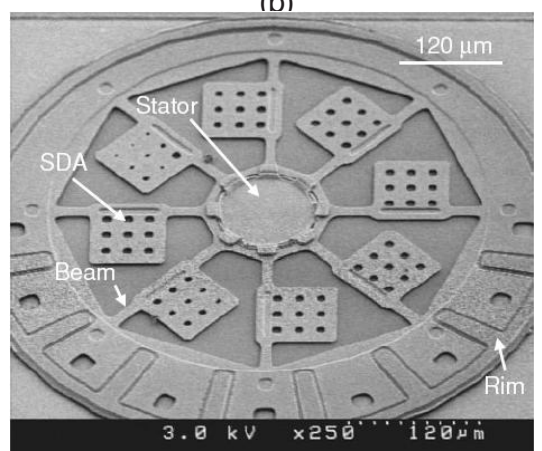

(d)

Figure 19. (a) An array of 8X8 Optical Cross Connect switches from Lee et al [50]. (b) Schematic illustration of SDA actuated flip-up mirror [50].(c) SDA driven cam-micromotor for optical switch with 'ON' and 'OFF' position Kanamori et al[54] (d) SDA driven cam-micromotor [54]

Helin et al.[55] presented a self-aligned bulk-micro-machined optical switch using a cantilever actuator. The vertical mirror is integrated to the tip of the silicon cantilever beam and V-grooves for optical fiber insertion and alignment are made in a single wet anisotropic silicon etch as shown in Figure 20. 


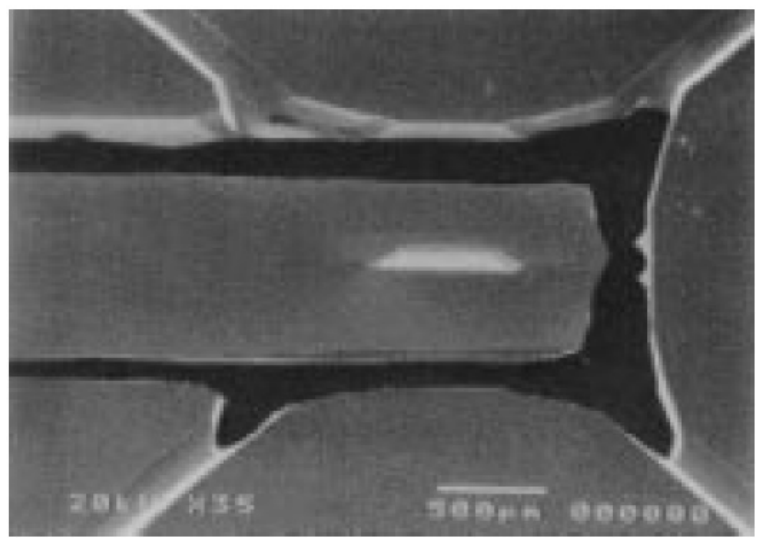

Figure 20. Bulk micro-machined self aligned 2X2 optical switch [55].

Electro-magnetically actuated vertical cantilever actuator is also used by Ji et al [56] to realize MEMS optical switch using DRIE technology as shown in Figure 21(a) and (b). The vertical cantilever beam is supported by torsion beams. The vertical micro-mirror, U-grooves with clip structures for optical fiber insertion and alignment, and actuation structures are all made in a single dry anisotropic etch.

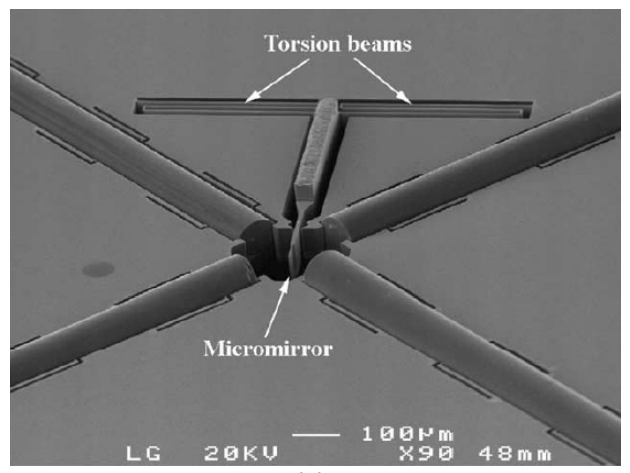

(a)

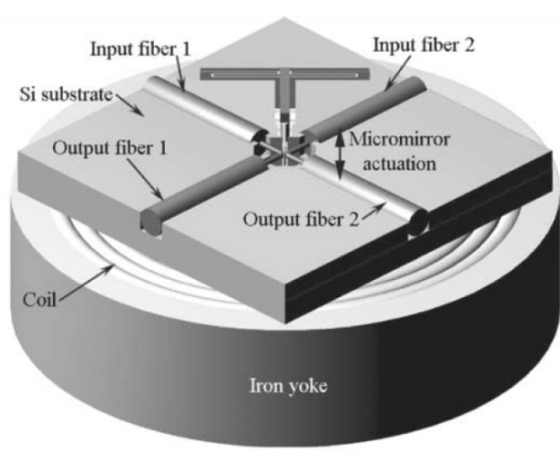

(b)

Figure 21. (a) $2 \times 2$ optical switch array from Ji et al [56] (b) illustration of magnetic field source and optical switch system[56]

The cantilever actuators such as the ones used by Helin et al [55] and Ji et al[56] are bi-stable as a result of employing permanent magnet in electro-magnetic actuation. Two-way out-of-plane actuation and low-voltage drivability are also other important features of these actuators.

Comb-drive actuator is commonly used for in-plane actuation. Marxer et al [57] used combdrive actuator to make an optical switch as shown in Figure 22. DRIE is used to form U-grooves 
for optical fibers insertion and alignment, the vertical mirror and the comb drive actuators in one mask step.

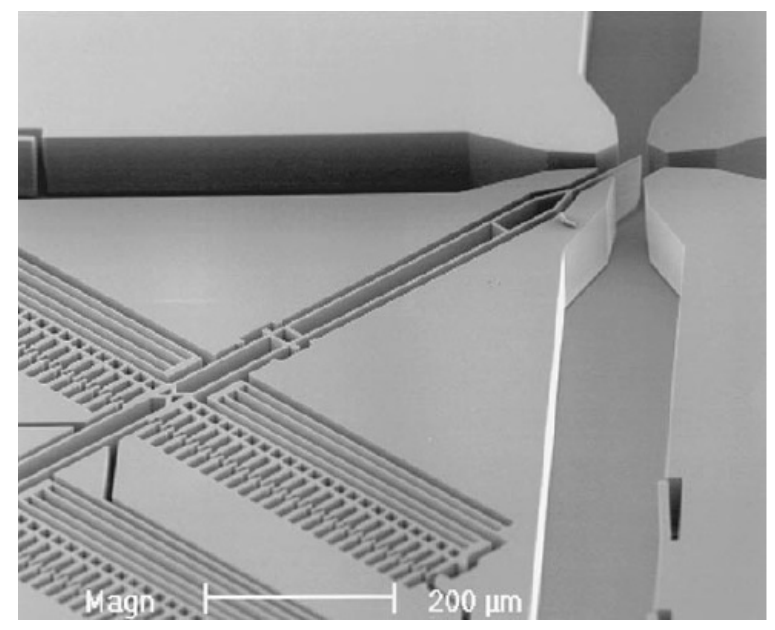

Figure 22. SEM of actuator-mirror system from Marxer et al [57]

\subsubsection{MEMS actuators for Guided-Wave 2-D MEMS optical switching}

Although MEMS actuators like comb-drives, cantilevers, and suspended plates have been used in planar waveguide switching, they are developed in a different fashion and actuation mechanism so that they can be appropriate to PLC applications. This is because the approach employed for free-space optical switching was not suitable for planar waveguide switching due to some fundamental differences.

- Large mirror sizes, commonly in the range of $200 \mu \mathrm{m}$, are required for optical fiber switches compared to small mirror sizes, in the range of $40 \mu \mathrm{m}-50 \mu \mathrm{m}$, for PLC depending on the beam waist. Related to this difference, SDA actuators used for optical fiber switching in [50-53] and Torsion beam and hinges in [58-59] are not appropriate for planar waveguide switching.

- Optical fibers are placed in and aligned using V-grooves (or U-grooves) in free space optical switches. These grooves can be precisely designed and fabricated to position the core of the fiber at any level relative to the surface of the wafer. The core can be positioned on or below the plane surface of the wafer. This flexibility of positioning optical fibers is not possible with planar waveguides. Planar waveguides are usually fabricated in a different substrate and assembled above the surface of the wafer. As a result of this inflexibility, cantilever actuators with electromagnetic actuation similar to those of Helin et al [55] and Ji et al [56] may not suitable for planar waveguide switching applications. 
- Figure 23(a) and (b) shows the comb-drive configuration used by Dellmann et al [60] for guided wave optical switching. The actuator, the mirror and the trenches were fabricated in one substrate using DRIE on SOI. The arrays of planar waveguides were fabricated on another substrate. The two wafers were then assembled together by aligning the waveguides into the trenches.

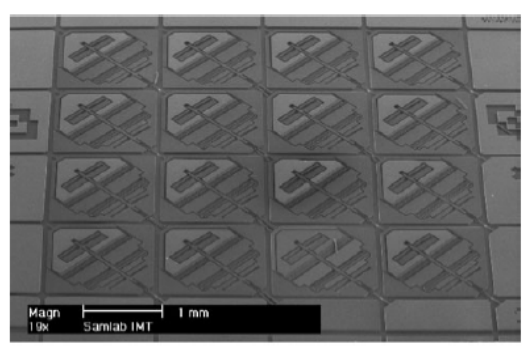

(a)

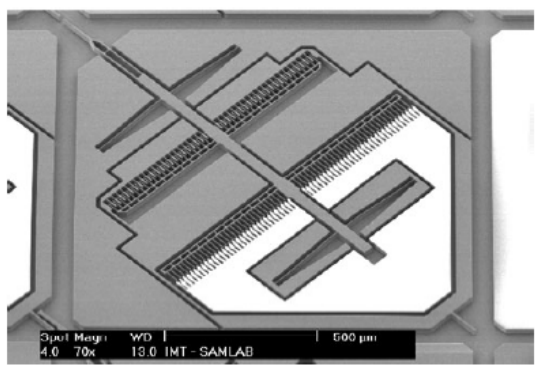

(b)

Figure 23. (a) planar waveguide optical switch matrix[60] (b) Single optical switch[60]

In another configuration for guided wave switching, an actuator consisting of a plate suspended by four symmetric beams (springs) is used by Iyer et al [61]. The actuator and a single switch arrangement are illustrated in Figure 24(a) and (b).

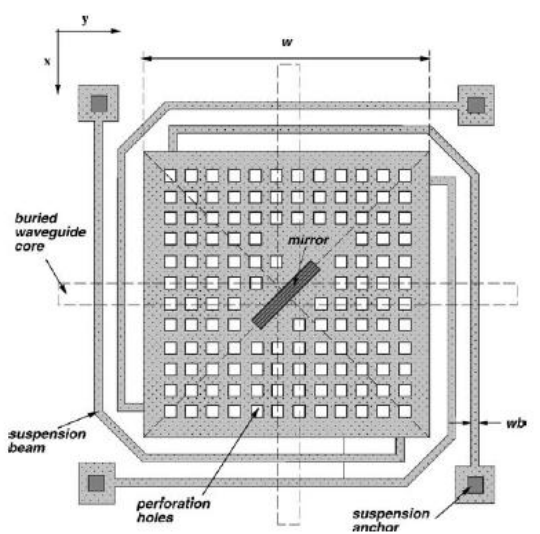

(a)

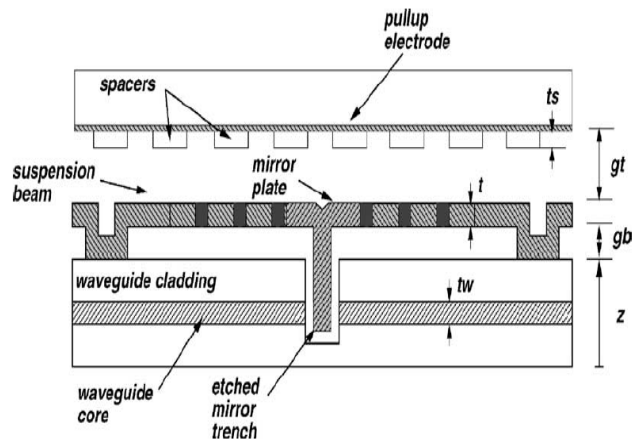

(b)

Figure 24. (a) illustration of actuator used and (b) a single planar waveguide optical switch from lyer et al[61].

Guerre et al. [62] used a simple cantilever and bridge actuator in the configuration shown in Figure 25(a) and (b) for PLC switching application. 


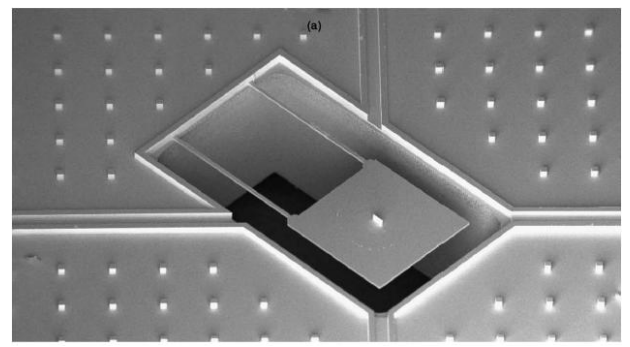

(a)

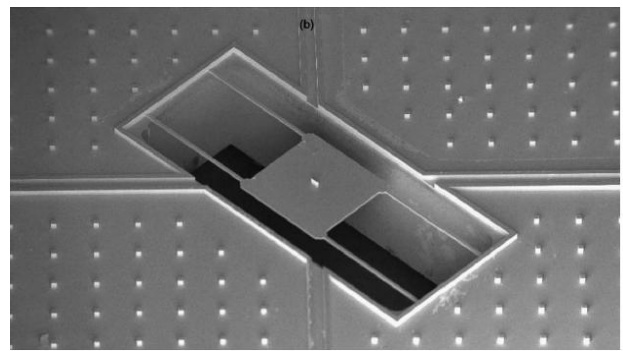

(b)

Figure 25. (a) Cantilever actuator with a micro-mirror[62] and (b) Bridge actuator with a micro-mirror Guerre et a/[62]

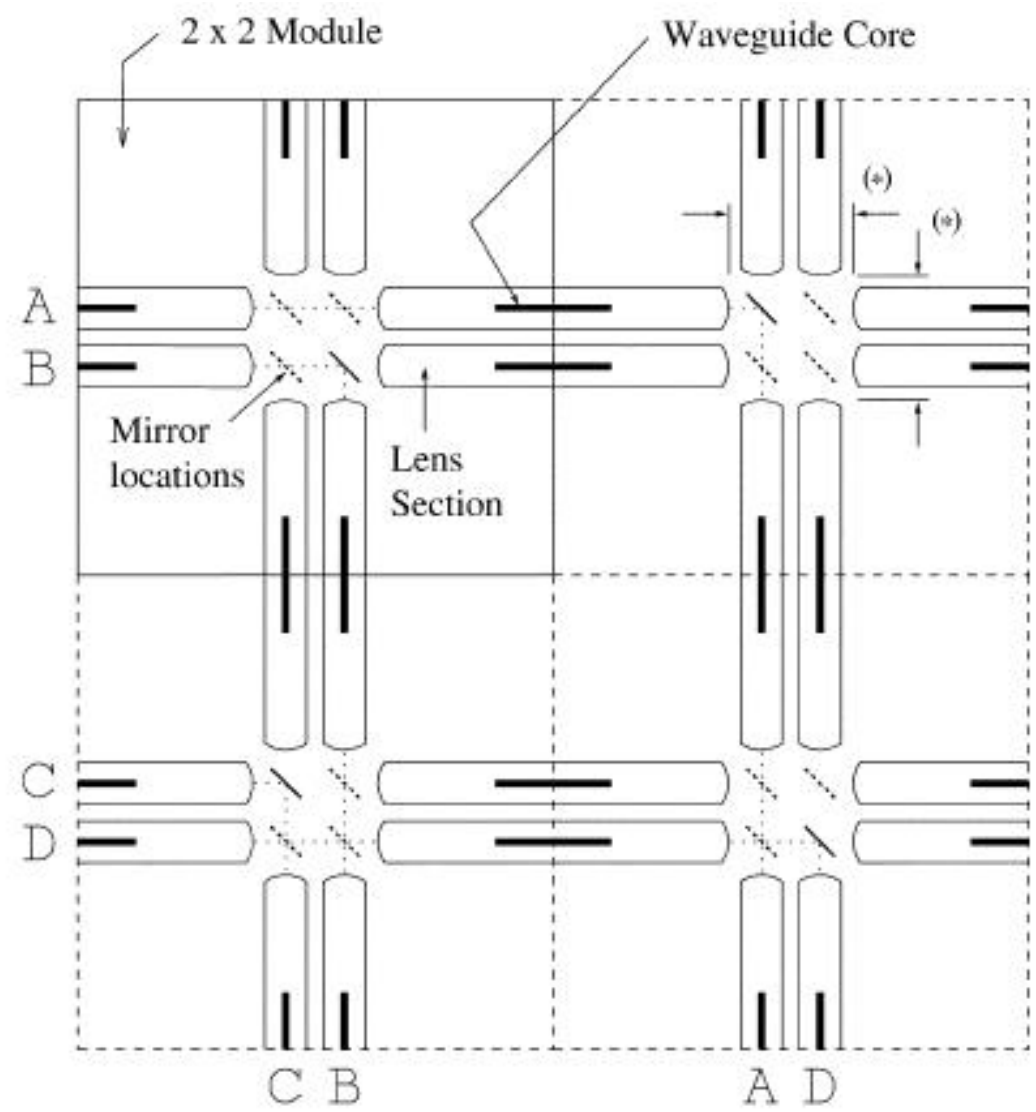

Figure 26. Optical switching architecture combining both Free space and guided wave features[63]. 


\subsubsection{Combined free space and guided-wave MEMS optical switching}

The major drawback of guided wave MEMS optical switching architectures is the requirement to employ two separate substrates to form the optical switch. This is mainly due to the incompatibility between the PLC and MEMS actuator fabrication processes employed in the guided wave optical switching schemes. Thus, developing MEMS actuation mechanism that is compatible with PLC fabrication processes is necessary to solve the drawback. Moreover, such actuation mechanism may enable to realize new optical switching architecture proposed by Mackenzie et al [63]. The architecture is based on planar lens pairs and their integration with MEMS actuation mechanism. It combines both free-space and guided wave approaches and is illustrated in Figure 26. It incorporates the advantages of simplicity in free-space architectures and large port count in guided wave approaches.

The same authors [64] later also suggested a 1X4 modular optical switching layout, which can be cascaded to make larger matrix optical switches. This switching layout, based on the planar lens pair, can theoretically minimize propagation loss regardless the matrix size. As a result, it is expected to provide a significant possibility of realizing multi-channel 2-D MEMS optical switching.
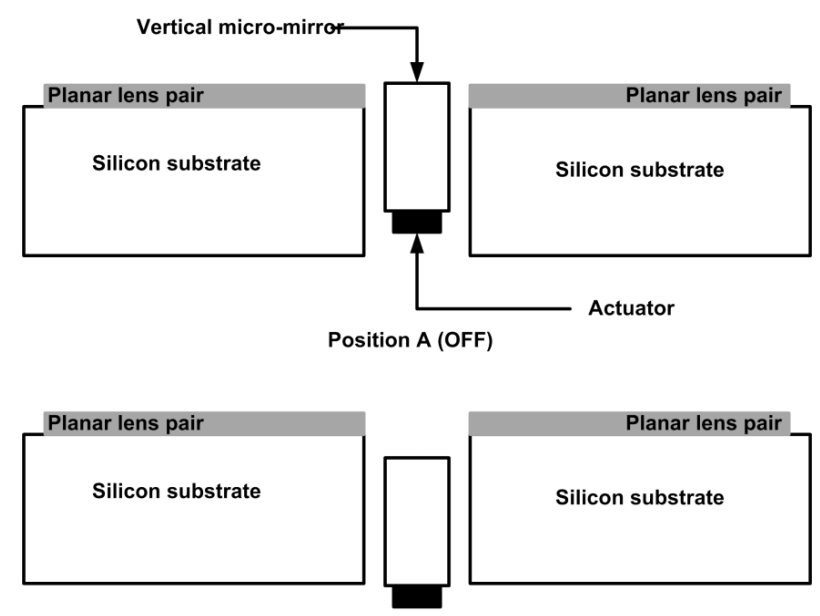

Position B (ON)

Figure 27. Desired positions of micro-mirror for planar lens pair optical switching

For such combined Free Space and guided-wave MEMS optical switching architecture to be realized, micro-mirror actuation mechanism that fulfills the following characteristics is required: (i) compatibility with planar lens fabrication process; (ii) large out-of-plane deflections; (ii) bistabilty. Figure 27 illustrates the switching positions of the micro-mirror actuation mechanism with respect to planar lens pairs. When the micro-mirror is moved to position A, it defines an OFF state. To switch ON the optical link between planar waveguides, the micro-mirror will be moved down to position B. Since bi-stability is desired for optical switch, the out-of-plane deflections that define the $\mathrm{ON}$ and OFF positions of the micro-mirror should be stable posi- 


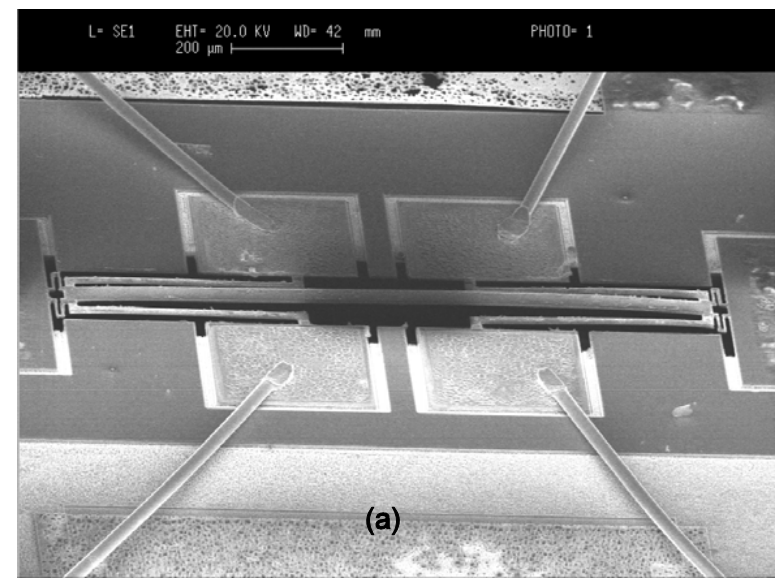

Figure 28. Bi-stable thermally actuated micro-bridge actuator

tions. Previously realized micro-mirror actuation mechanism for free space or guided wave MEMS optical switches do not fulfill the above requirements, and hence are not suitable for planar silica lens. Bi-stable thermally actuated micro-bridge [65] has been developed to enable micro-mirror actuation mechanism that is compatible with planar lens pairs fabrication process steps and provides the required out-of-plane movement. Figure 28 shows the SEM image of thermally actuated micro-bridge actuator. The actuator has $1200 \mu \mathrm{m}$ length, $80 \mu \mathrm{m}$ width, and $5.5 \mu \mathrm{m}$ effective thickness. It has provided $30 \mu \mathrm{m}$ range of out-of-plane movement. The fabrication process [65] is based on releasing a silicon membrane on which the micro-bridge is defined using wet anisotropic TMAH silicon etch with electro-chemical etch stop. When the micromirror is integrated with the micro-bridge, the length of the micro-bridge is increased to compensate for the size of the mirror that integrates to the mid-portion of micro-bridge. In addition, the effective length, the length of the micro-bridge minus the length the mirror, should be chosen to provide the required out of plane movements for optical switching. In the case of planar silica lens with $\mathrm{d}_{\mathrm{T}}=200 \mathrm{um}$, the micro-mirror must travel at least $24 \mu \mathrm{m}$ (the thickness of the planar lens) out-of-plane from the surface of substrate in order to fully intercept the optical path for either ON or OFF switching operation. Not only the mirror is required to be moved at least by 24 um out-of-plane but also it should stay in that position without requiring power for bi-stability operation. In other words, the micro-bridge should provide at least $24 \mu \mathrm{m}$ initial outof-plane deflection. Based on buckling behavior [66] and bi-stability criteria [67] of the microbridge, the effective length of $1500 \mu \mathrm{m}$ has been calculated. The fabricated micro-mirror actuator designed for such purpose is shown in Figure 29. The vertical mirror is monolithically integrated with micro-bridge. The mirror has an initial out-of-plane deflection of $27 \mu \mathrm{m}$ as seen from SEM image taken at $80^{\circ}$ tilt in Figure 30, and confirmed by MSA Polytech surface analyzer. For this monolithic integration of micro-mirror, (110) oriented silicon wafer with the primary flat in (111) is used. This enables to form vertical micro-mirror with sidewall having (111) orientation. Other (111) planes at $35.6^{\circ}$ from the sides also emerge. The final shape of the micro-mirror is more like trapezoidal than a perfect rectangle with the top length of $100 \mu \mathrm{m}$ and bottom length of around $850 \mu \mathrm{m}$ for $270 \mu \mathrm{m}$ thick silicon substrate. The total length of the micro-mirror actuator 
is, therefore, about $2350 \mu \mathrm{m}$ as can be measured from Figure 29. The optical characterization of the micro-mirror actuator [14] has demonstrated less than $0.9 \mathrm{~dB}$ optical insertion loss during ON state and more than $60 \mathrm{~dB}$ isolation loss during OFF state at $1.3 \mu \mathrm{m}$ wavelength. Combining this micro-mirror actuator with planar lens pairs in 1X4 modular optical switch architectures can provide optical switch with the maximum optical loss of only $2.46 \mathrm{~dB}$. The optical switch can be extended to $2 X 4$ matrix with the maximum loss of $4.02 \mathrm{~dB}$. The maximum loss for any NX4 matrix based on $1 \mathrm{X} 4$ modular unit is $2.46+(\mathrm{N}-1) * 1.56$. For an allowable optical loss of $16 \mathrm{~dB}$, for example, the optical switch matrix can be extended to 9X4.

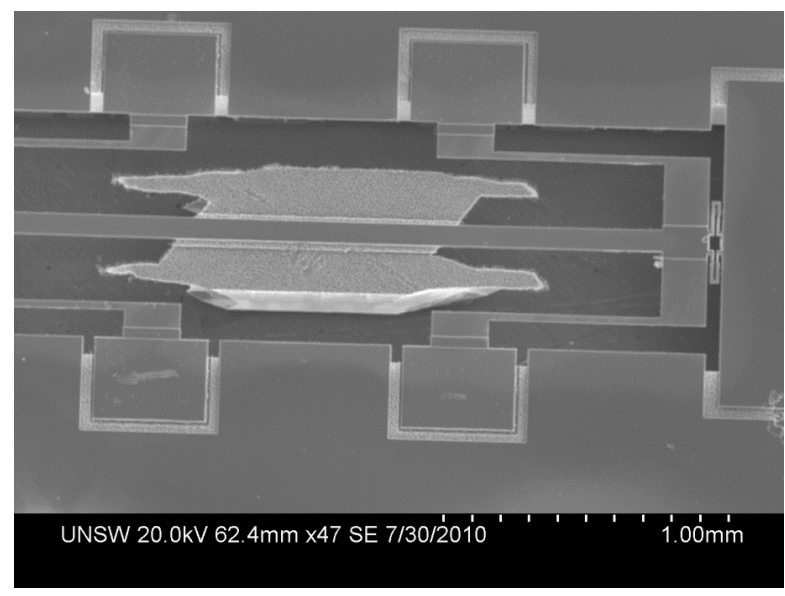

Figure 29. The micro-mirror actuator with monolithically integrated vertical micro-mirror.

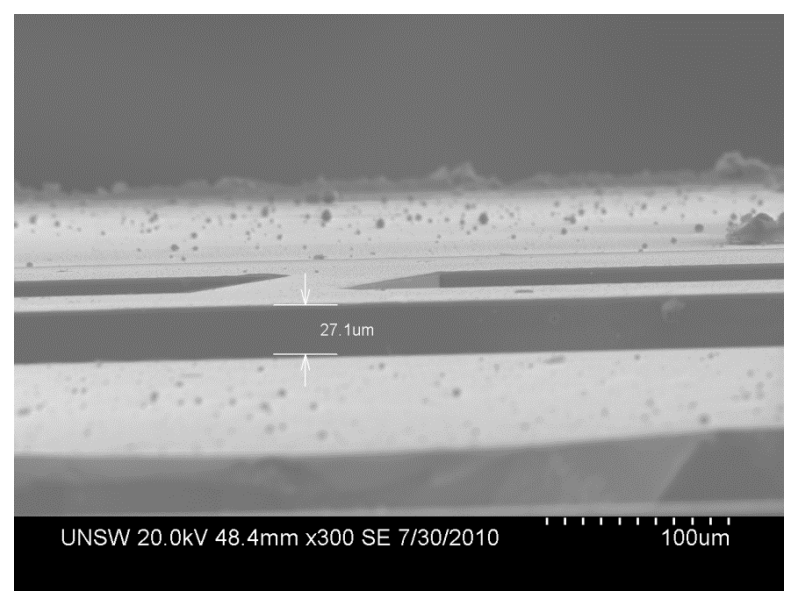

Figure 30. Initial out-of-plane deflection of micro-mirror as viewed at $80^{\circ}$ tilt 


\subsection{MEMS based 3D optical interconnect}

Optical link has provided a solution to bandwidth limitation exhibited by wire link. It has been found to be effective when the length of the link is substantial depending on the data speed. Optical link is now ubiquitous form of interconnect for switching nodes in telecommunication network, and for rack to rack communication. As the communication speed goes beyond 10GHz, optical links for board-to-board communication on the PCB and core-to-core communication on multi-core process on a single chip become viable solutions not only to resolve the bandwidth limitation of wire interconnects but also to reduce cost and save power consumption. As the number of cores in multi-core architecture increases, it is envisaged that communication speed in order of THz will be reached. Although TSV (Through Silicon Via) technology is used to reduce the wire interconnect distance between integrated circuits in 3D stack to increase bandwidth, it is inevitable that optical link in 3D stack will be cost driven solution. A number of solutions have been proposed to create such optical link. One of these solutions involves optical propagation in free-space. Focusing elements are required for low-loss free space optical link. Focusing techniques based on Micro-ball lens [68], fluidic membrane lens [69], a planar PDMS lens [70] and a polymer lens [71] are not compatible with planar waveguides and requires separate assembly processes. Planar silica lens pair discussed earlier in this chapter is well suited for such purpose. The integration of this planar lens in the 3D optical interconnect system has been demonstrated [72].

The 3D optical interconnect system employs a pair of $45^{\circ}$ micro-mirrors in order to establish an optical path between stacked silicon dies, as illustrated schematically in Figure 31 . The fabrication processes have been developed to form both facing-down and facing-up $45^{\circ} \mathrm{mi}-$ cro-mirrors. The formation of ultra-smooth facing-up $45^{\circ}$ micro-mirrors using surfactant added low concentration TMAH has been established [11]. The process starts with p-type (100) silicon wafer with primary flat in (110) direction. The silicon wafer is then thermally oxidized to grow silicon dioxide. The grown oxide is patterned to expose silicon surface using a rectangular mask rotated by $45^{\circ}$ from the primary flat so that its edge can orient in (100) direction. Performing wet silicon etch in surfactant added (1\%) low TMAH concentration $(5 \%)$ with successive removal of over-hanging oxide mask produces ultra-smooth $45^{\circ}$ micro-mirror whose surface is in (110) plane. Figure 32(a) shows the SEM cross-sectional view for the fabricated $45^{\circ}$ facing-up micro-mirror.

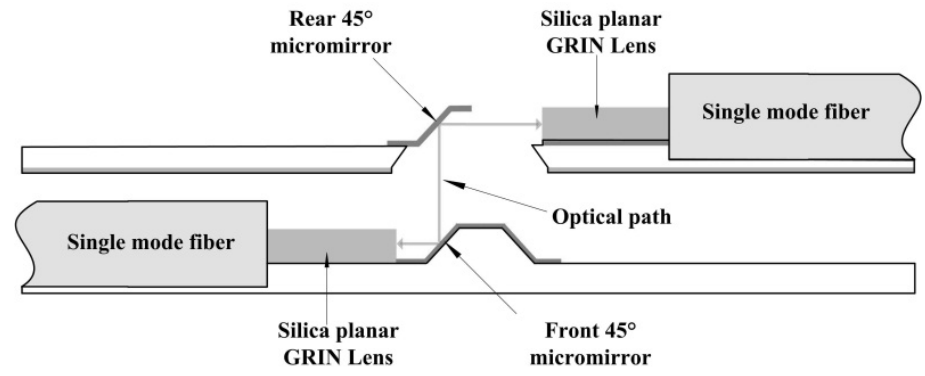

Figure 31. Optical interconnect system with planar silica lens pairs 

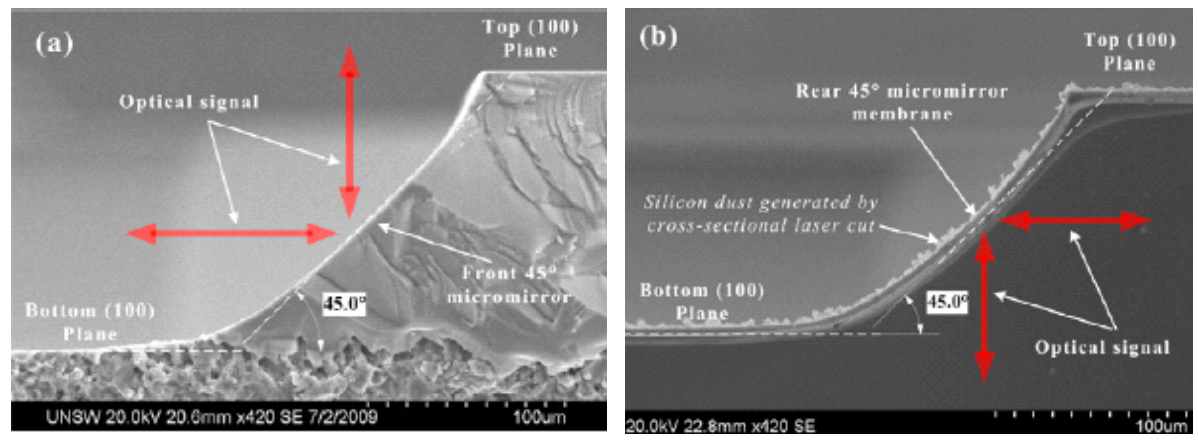

Figure 32. (a) Facing-up $45^{\circ}$ micro-mirror; (b) Facing-down $45^{\circ}$ micro-mirror

Based on the formation of facing-up $45^{\circ}$ micro-mirrors, phosphorus diffusion on p-type substrate on the side where the facing-up $45^{\circ}$ micro-mirror is formed, and electro-chemical etch stop technique at p-n junction, facing-down $45^{\circ}$ has been released[73]. The cross-sectional view of the released facing-down $45^{\circ}$ micro-mirror is shown in Figure 32(b).

The fabrication techniques to form facing-up and down $45^{\circ}$ micro-mirrors have been modified to integrate planar silica lens pairs and U-grooves for single-mode optical fiber insertions [74, 75]. Figure 33 and 34 show the modified fabrication process steps for integrating planar lens pairs with facing-up and facing-down $45^{\circ}$ micro-mirror, respectively.
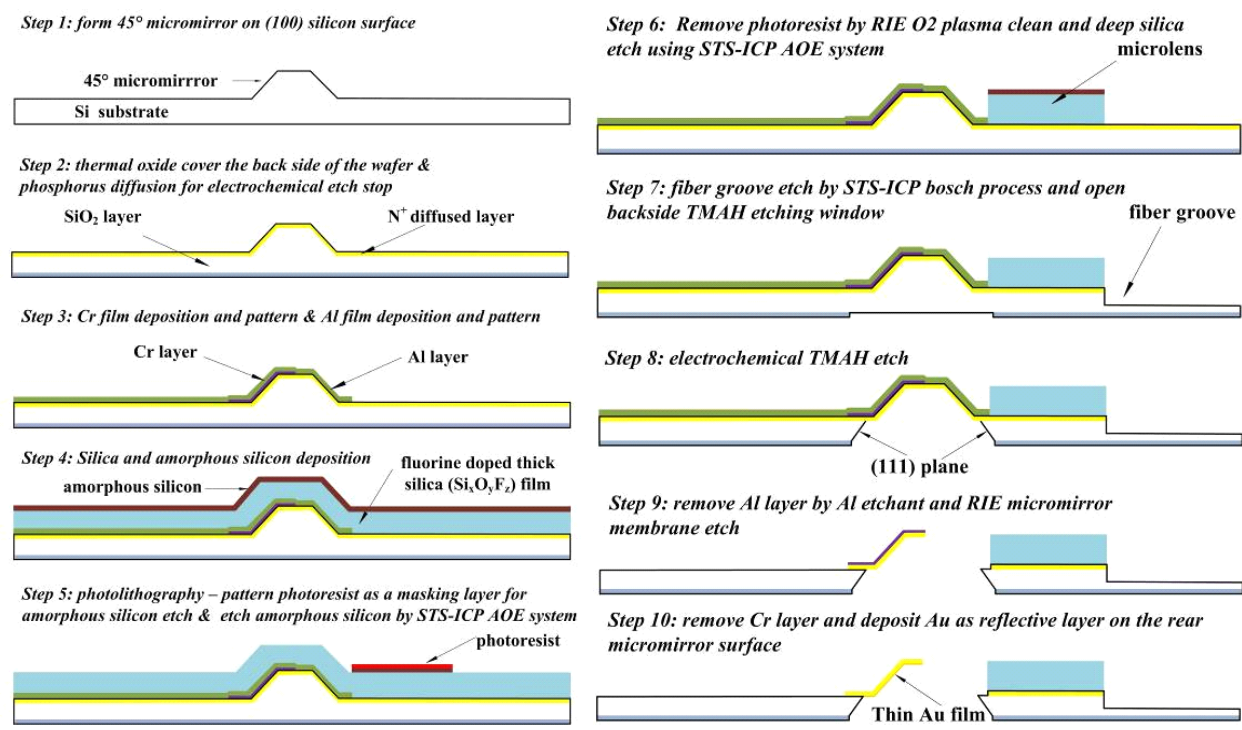

Step 7: fiber groove etch by STS-ICP bosch process and open
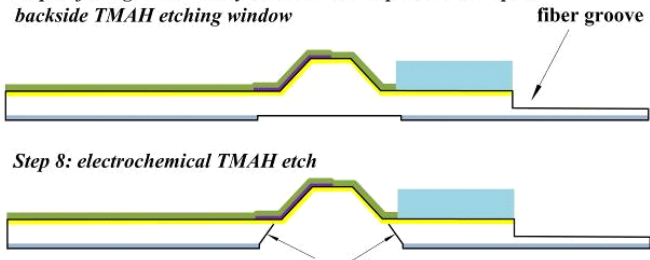

(111) plane

Step 9: remove Al layer by Al etchant and RIE micromirror membrane etch
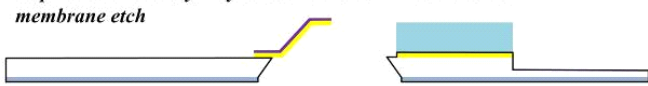

Step 10: remove Cr layer and deposit Au as reflective layer on the rear micromirror surface

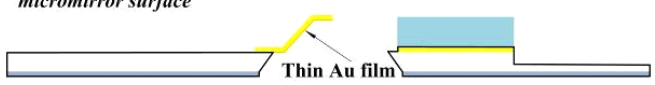

Figure 33. Fabrication process flow for silica lens integrated facing-down $45^{\circ}$ micromirror. 
It should be noted that in both fabrication process steps, the thick silica film deposition and micro-machining techniques are based on the discussion we had earlier in section 4 . In this case, however, the planar lens pair designed for a free-space propagation distance of $500 \mu \mathrm{m}$ is employed. The SEM images of the fabricated top die consisting of the facing-down micromirror and one of the planar lens pair and bottom die having facing-up micro-mirror and the other planar lens pair are given in Figure 35 and 36, respectively.
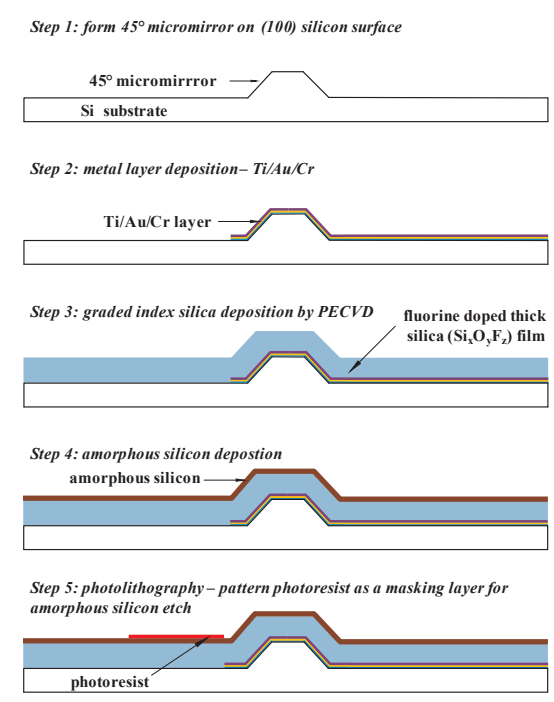

Step 6: amorphous silicon etch by STS-ICP AOE system

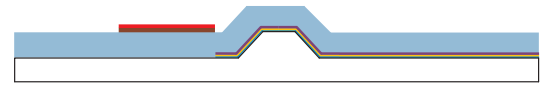

Step 7: remove photoresist by wet or dry clean processes

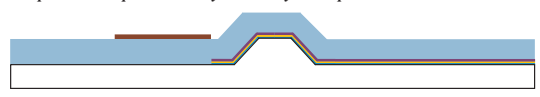

Step 8: deep silica etch using STS-ICP AOE system

microlens

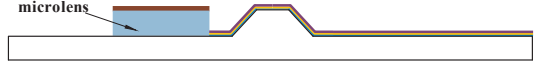

Step 9: fiber groove etch by STS-ICP bosch process

fiber groove

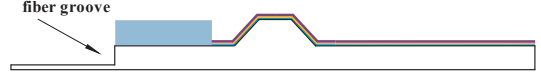

Step 10: expose Au reflective layer by removing Cr layer

Au/Cr layer

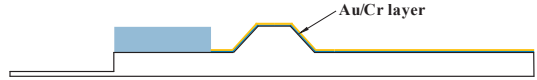

Figure 34. Fabrication process flow for silica lens integrated facing-up $45^{\circ}$ micromirror. 


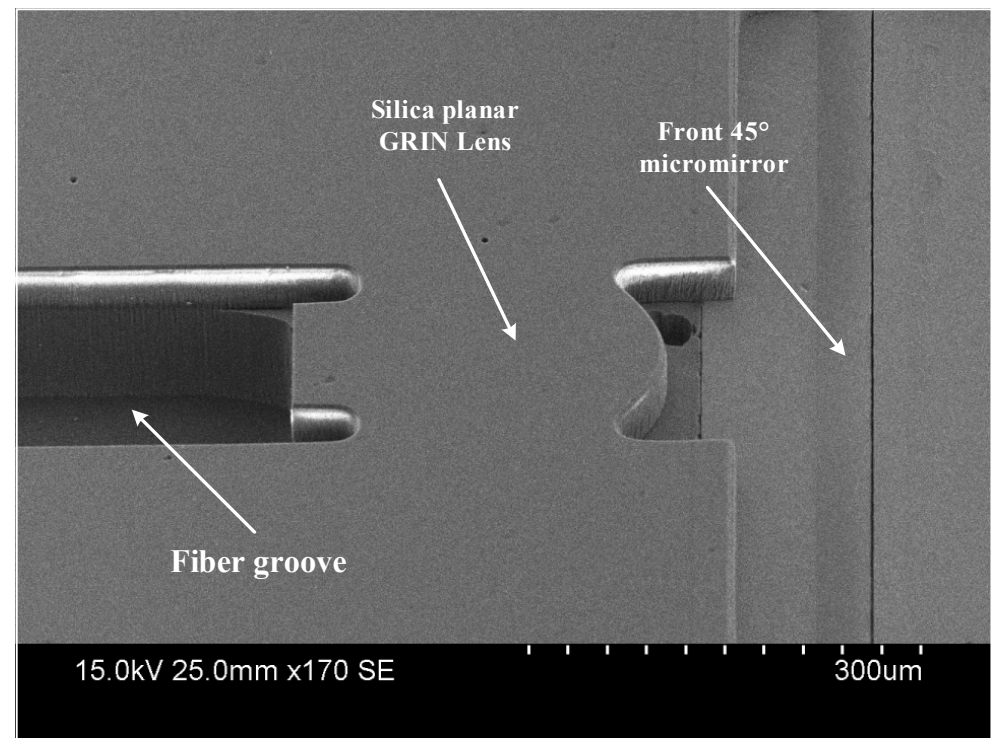

Figure 35. Front facing micromirror with planar silica graded index lens.

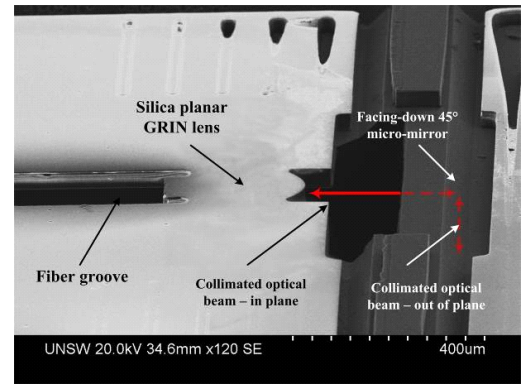

(a)

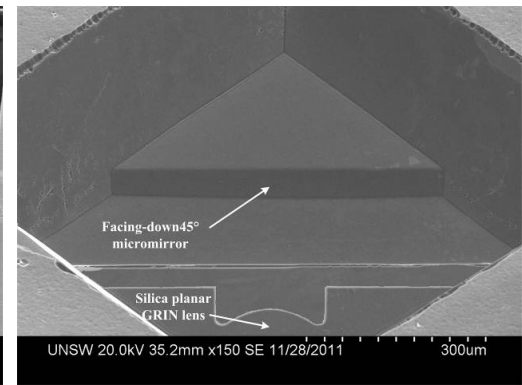

(b)

Figure 36. (a) SEM image of silica planar GRIN lens integrated with facing-down $45^{\circ}$ micro-mirror.Flerioof silica planar; (b) backside view of facing-down $45^{\circ}$ micro-mirror

After fabricating the top and bottom dies separately, they are assembled and aligned one on the top of the other using micro-positioning system. Input and output single mode optical fibers are inserted into the U-grooves formed on the dies and butt-coupled to the respective planar lenses. The input optical fiber is coupled to the pig-tailed laser diode source at $633 \mathrm{~nm}$ wavelength. The output fiber is coupled to optical power to measure the received power. The total optical power loss in the system is measured to be $8.5 \mathrm{~dB}$. This is an improvement of more than $25 \mathrm{~dB}$ and demonstrates the effectiveness of the planar silica GRIN lens in reducing optical loss in 3D optical interconnect systems. 


\section{Author details}

A. Michael, C.Y. Kwok, Md. Al Hafiz and Y.W. Xu

School of Electrical Engineering and Telecommunication, UNSW, Australia

\section{References}

[1] H.Robbins and B.Schwartz, "Chemical Etching of Silicon-II: The system $\mathrm{HF}, \mathrm{HNO}_{3}$, $\mathrm{HC}_{2} \mathrm{C}_{3} \mathrm{O}_{2}$," J. Electrochem. Soc.,vol. 107, pp. 108-11, 1960.

[2] H.Muraoka, T.Ohahi, and T.Sumitomo, "Controlled Preferential Etching Technology," in semiconductor silicon 1973, Chicago, pp. 327-38

[3] Marc J. Madou, Fundamentals of Microfabrication, second edition

[4] G.T.Kovacs, N.I.Maluf, and K.E. Peterson, "Bulk Micromachining of Silicon," in proceedings of the IEEE, Vol. 86, IEEE, 1998, pp. 1536-51.

[5] B.Schwartz, and H.Robbins, "Chemical etching of Silicon-IV: Etching Technology," J.Electrochem. Soc.,Vol. 123, pp. 1903-9,1976.

[6] H. Seidel, L.Csepregi,A.Heuberger, H. Baumgartel, “Anisotropic etching of crystalline silicon in alikaline solutions. Part I. Orientation dependence and behaviour of passivation layers. Journal of the Electrochamical Society 137, pp. 3612-3626.

[7] M. Elwenpoek, H.V. Jansen, Silicon Micromachining, Cambridge university press.

[8] R.J.Jaccodine, "Use of modified free energy theorems to predict equilibrium growing and etching shapes," Journal of Applied Physics, 33(1962), pp.2643-2647.

[9] Martin Hoffman, Sabine Dickhut, and Edgar voges, "Fiber Ribbon Alignment Structures Based on Rhombus Shaped Channels in Silicon," IEEE Photonics Technology Letters, Vol. 12, No.7, (2000), pp. 828-830.

[10] D.Cheng, M.A.Gosalvez,T.Hori, K.Sato, M.Shikida, "Improvement in smoothness of anisotropically etched silicon surfaces: effects of surfactant and TMAH concentrations," Sensors and Actuators A: Physical, Vol. 125, (2006), pp. 415-421.

[11] Y.W.Xu, A.Michael, C.Y.Kwok, “Formation of ultra-smooth $45^{\circ}$ micromirror on (100) silicon with low concentration TMAH and surfactant: Technique for enlarging the truly $45^{\circ}$ portion," Sensors and Actuators A: Physical, Vol.166 (2011),pp. 164-171.

[12] Philippe Helin, Makoto Mita, Tarik Bourouina, Gilbert Reyne, and Hiroyuki Fujita, "Self-Aligned Micromachining Process for Large-Scale, Free-Space Optical CrossConnects," Journal of Light wave Technology, Vol. 18, No. 12, 2000, pp. 1785-1791. 
[13] Shi-sheng Lee, Long-sun Huang, Chang-Jin Kim, and Ming C. Wu, "Free-Space Fiber-Optic Switches Based on MEMS Vertical Torsion Mirrors," Journal of Lightwave Technology, Vol. 17, No. 1, January 1999, pp. 7-12.

[14] A.Michael, C.Y.Kwok, "Monolithically integrated out-of-plane micro-mirror," Sensors and Actuators A: physical, Vol.179, pp. 263-276, 2012.

[15] Martin Hoffman and Edgar Voges, "Bulk Silicon Micromachining for MEMS in optical communication systems," Journal of Micromechanics and Micro engineering, Vol. 12 (2002) pp. 349-360.

[16] C.Strandman, L.Rosengren,H.G.A. Elderstg, Y.Backlund, "Fabrication of $45^{\circ}$ mirrors together with well-defined V-grooves using wet anisotropic etching of silicon," Journal Microelectro mechanical systems, 4(4) (1995), 75-79.

[17] H.F.Winters and J.W.Coburn, " The etching of silicon with $\mathrm{XeF}_{2}$ vapor," Applied Physics Letter, Vol.34, No.1,pp 70-73,1979.

[18] R.S.Osgood, Jr., H. H. Gilgen, and P. Brewer, "summary abstract: Low temperature deposition and removal of material using laser-induced chemistry," J. Vac. Sci Technology ,, Vol. 2, no. 2, pp. 504-505, Apr.-June 1984.

[19] J.W.Coburn and H.F.Winters, "Plasma etching- A discussion of mechanisms," J.Vac. Sci. Tehcnology, Vol. 16, no. 2, pp. 391-403,Mar./Apr 1979.

[20] M.H.Hecht, R.P.Vasquez, and F.J.Grunthaner, “ A novel x-ray photoelectron spectroscopy study of the $\mathrm{Al} / \mathrm{SiO}_{2}$ interface," J.Appl. Phys., Vol.57, no. 12, pp. 5256-5261, 1985.

[21] E.Hoffman, B.Warneke, E.Kruglick, and K.S.J.Pister, “3D structure with piezoresistive sensors in standard CMOS," in Proc. IEEE Micro Electro Mechanical Systems Conf., Amsterdam, The Netherlands, Jan. 29-Feb. 2, 1995, pp. 288-293.

[22] U.Kohler, A.E.Guber, W.Bier, M.Heckele, and Th.Schaller, "Fabrication of microlenses by combining silicon technology, mechanical micromachining and plastic molding," in Proc. SPIE Miniaturized Systems with Micro-Optics and Micromechanics, San Jose, CA, Jan. 30-31, 1996, Vol. 2687, pp. 18-22.

[23] K.Murakami, Y.Wakabayashi, K.Minami, and E.Esashi, “Cryogenic dry etching for high aspect ratio microstructures," in Proc. IEEE Microelectromech. Syst. Conf., Fort Lauderdale, FL, Feb. 1993, pp. 65-70.

[24] M.Esashi, M.Takinami, Y.Wakabayashi, and K.Miniami, "High-rate directional deep dry etching for bulk silicon micromachining," J.Micromech Microeng, Vol. 5, No. 1, pp. 5-10, Mar. 1995.

[25] F.Larmer and P.Schilp, "Method of anisotropically etching silicon," German Patent DE 4 241045, 1994. 
[26] Chang-Hyeon Ji, Youngjoo Yee Yunghoon Choi, Seong-Hyok Kim, and Jong-Uk Bu, "Electromagnetic 2X2 MEMS Optical Switch," IEEE Journal of selected topics in quantum electronics, Vol. 10, No. 3, 2004, pp 545-550.

[27] Cornel Marxer and Nicolaas F. de Rooij, "Micro-Opto-Mechanical 2 X2 switch for Single Mode Fibers Based on Plasma-Etched Silicon Mirror and Electrostatic," Journal of Lightwave Technology, Vol. 17, No.1, 1999, pp. 2-6.

[28] M.V.Bazylenko, M.Gross, A.Simonian and P.L.Chu, "Pure and Flourine-doped silica films deposited in a hollow cathode reactor for integrated optic applications, J.Vacuum Sci.Technology. A, 14(1996), 336-345.

[29] M.V.Bazylenko, M.Gross, P.L.Chu, and D. Moss, "Photosensitivity of Ge-doped silica deposited by hollow cathode PECVD," Electron Letter, 32(196), 1198-1199.

[30] M.R. Mackenzie, "collimating lens pair for planar silica waveguides" PhD Thesis, 2005, University of New South Wales, NSW, Australia.

[31] A.Michael, Md.Hafiz, T.Puzzer, C.Y.Kwok, “Fabrication and optical characterization of planar silica lens pair," Electron Letter,2011, 46(21), pp. 1459-1460.

[32] D.R.Betltrami, J.D.Love, A.Durandet, A.Samoc, M.Samoc, B.Luther-Davies and R.W.Boswell, “Planar graded-index (GRIN) PECVD lens," Electron letter, 32(1996), pp. 548-550.

[33] X. Zhang, K.-S. Chen, R.Ghodssi, A.A.Avon, and S.M Spearing, "Residual stress and fracture in thick tetraethylorthosilicate (TEOS) and silane-based PECVD oxide films," Sensors and Actuators A, 91(2001), pp.379-386.

[34] Patrick J. French et al, "The development of a Low-Stress Polysilicon Process Compatible with Standard Device Processing, " Journal of Microelectromechanical Systems, Vol. 5, No. 3, September 1996.

[35] Md.Al Hafiz, A.Michael, C.Y.Kwok and T. Puzzer, "Fabrication and optical characterization of planar silica lens pair," Electronics Letters, Vol. 46, No. 21, 2010 pp.

[36] N.R.Rueger, M.F.Doemling, M.Schaepkens, J.J.Beulens, T.E.F.M.Standaert, and G.S.Oehrieina, "Selective etching of $\mathrm{SiO}_{2}$ over polycrystalline silicon using $\mathrm{CHF}_{3}$ in an inductively coupled plasma reactor," J.Vac.Sci. Technology A, Vol 17, No.5, 1999, pp. 2492-2502.

[37] D.Bien et al, "Characterization of masking materials for deep glass micromachining," J. Micromech. Microeng. 13 (2003) 34-40.

[38] Md. Abdullah Al Hafiz, Mark R. Mackenzie, Chee Yee Kwok, “Design Methodology of focusing elements for multilevel planar optical systems in optical interconnects," Optical Engineering, 48(12), 2006,125401-(1-9).

[39] P.D.Dobbelaere, K.Falta, L.Fan, S.Gloeckner, and S.Patra, “Digital MEMS for optical switching," IEEE Commun.Mag., pp. 88-95, Mar.2002. 
[40] A.Dugan, L.Lightworks, and J.-C.Chiao, “The optical switching spectrum: A primer on wavelength switching technologies," Telecommunication Mag., May 2001.

[41] J.Sapriel, D.Charissoux, V.Voloshinov, and V.Molchanov, "Tunable acoustooptic filters and equalizers for WDM applications," Journal of Lightwave Technology, vol. 20, pp.892-899, May 2002.

[42] B.Mukherjee, Optical Communication Networks. New York: Mc-Graw-Hill, 1997.

[43] J.L.Jackel, J.J.Johnson, and W.J.Tomlinson, "Bistable optical switching using electrochemically generated bubbles," Opt.Lett.,vol. 15, no.24, pp. 1470-1472, Dec. 1990.

[44] M.Makihara, M.Sato, F.Shimokawa, and Y.Nishida, "Micromechanical optical switches based on thermocapillary integrated in waveguide substrate," J.Lightwave technology, Vol.17, No.1, pp.14-18, Jan. 1999.

[45] J.E.Fouquet, S.Ventkatesh, M.Troll, D.Chen, S.Schiaffino, and P.W.Barth, "Compact, scalable fiber optic cross-connect switch using total internal reflection due to thermally-generated bubbles," in Proc. IEEE/LEOS Annu. Meeting, Orlando, FL, 1998, pp.169-170.

[46] P.B.Chu, S.Lee, and S.Park, "Mems: The path to large optical cross connects," IEEE Communication Magazine, pp.80-87, March 2002.

[47] J.Kim et al, "1100x1100 port mems-based optical crossconnect with 4-db maximum loss," IEEE Photonics Technology Letters, Vol.15, no.11, pp.1537-1539, 2003.

[48] T.Akiyama and K.Shono, "Controlled Stepwise Motion in Polysilicon Microstructures," IEEE JMEMS, Vol.2, No.3, pp. 106-110 Sep.1993.

[49] T.Akiyama and H.Fujita, "A Quantitative Analysis of Scratch Drive Actuator Using Buckling Motion," in IEEE workshop of MEMS, Amestrdam, The Netherlands, Jan. 29-Feb.2, 1995.

[50] L.Y.Lin, E.L.Goldstein, R.W.Tkach, “Free-Space Micromachined Optical Switches for Optical Networking", IEEE Journal of Selected Topic in Quantum Electronics, Vol.5, pp. 4-9, 1999.

[51] L.Y.Lin, E.L.Goldstein, R.W.Tkach, “ On the Expandability of Free-Space Micromachined Optical Cross Connects", Journal of Lightwave Technology, Vol 18, No.4, 482-489, 2000.

[52] S.S.Lee,L.S.Haung,C.J.Kim and M.C.Wu, "Free-Space Fiber-Optic Switches Based on MEMS Vertical Torsion Mirrors", Journal of Lightwave Technology, Vol.17, pp 7-14, 1999.

[53] R.T.Chen, H.Nguyen, M.C.Wu, “A High-Speed Low-Voltage Stress-Induced Micromachined 2X2 Optical switch", IEEE Photonics Technology Letters, Vol.11, pp. 1396-1399, 1999. 
[54] Y.Kanamori, Y.Aoki, M.Sasaki, H.Hosoya, A.Wada, and K.Hane, "Fiber-Optical Switch using Cam-Micromotor Driven by Scratch Drive Actuators," Journal of Micromechanics and Microengineering, vol.15, pp. 118-123, 2005.

[55] P.Helin,M.Mita,T.Bourouina,G.Reyne, and H.Fujita, “Self Aligned Micromachining Process for Large-Scale, Free-Space Optical Cross-Connects", Journal of Lightwave technology, vol.18, pp.1785-1791, 2000.

[56] C.H.Ji, Y.Yee, J.Choi, S.H.Kim, and J.U.Bu, "Electromagnetic 2X2 MEMS Optical Switch", IEEE Journal of Selected Topics in Quantum Electronics, Vol.10, pp.545-550, 2004.

[57] C.Marxer, C.Thio, M.A.Gretillat, N.F.de rooij, R.Bättig, O.Anthamatten, B.Valk and P.Vogel, "Vertical Mirrors Fabricated by Deep Reactive Ion Etching for Fiber-Optic Switching Applications", Journal of MicroElectroMechanical Systems, Vol.6, pp. 277-285.

[58] H.Toshiyoshi and H.Fujita, "Electrostatic Micro Torsion Mirrors for an Optical Switch Matrix", Journal of MicroElectroMechanical Systems, Vol.5, pp. 231-237, 1996.

[59] D.A.Horsley, W.O.Davis, K.J.Hogan, M.R.Hart, E.C.Ying, M.Chaparala, B.Behin,M.J.Daneman and M-H Kiang, "Optical and Mechanical Performance of a Novel Magnetically Actuated MEMS-Based Optical Switch", Journal of Microelectromechanical systems, Vol 14, pp.274-284.

[60] L.Dellmann, W.Noell, C.Marxer, K.Keible, M.Hoffmann, and N.F.De Rooij, “4x4 Matrix switch based on MEMS switches and integrated waveguides", in Proc. Transducers, Munich, Germany, Jun. 10-14, pp.1332-1335,2001.

[61] N.Iyer, C.H.Mastrangelo, S.Akkaraju,C.Brophy,T.G.McDonald, R.Dureiko, and E.T.carlen, "A two-dimensional optical cross-connect with integrated waveguides and surface micromachined cross-bar switches", Sensors and Actuators A: physical, Vol.109, pp.231-241, 2004.

[62] R.Guerre, C.Hibert,Y.Burri,Ph.Flückiger,P.Renaud, “Fabrication of vertical digital silicon optical micromirrors on suspended electrode for guided-wave optical switching applications", Sensors and Actuators A: physical, Vol. 123-124, pp. 570-583, 2005.

[63] M.R.Mackenzie and C.Y.Kwok, "Theoretical analysis of integrated collimating waveguide lens," IEEE Journal of Lightwave Technology, vol.21, no.4,pp.1046-1052, 2003.

[64] M.Mackenzie, "Collimating lens pair for planar silica waveguides", Ph.D thesis, School of Electrical Engineering and Telcommunication, The university of New South wales, May 2005.

[65] A.Michael, C.Y.Kwok, K.Yu, and M.Mackenzie, "A Novel Bi-stable Two-Way Actuated Out-of-Plane Electro-Thermal Micro-Bridge," IEEE Journal of MEMS, Vol.17, No. 1,pp. 58-69, 2008. 
[66] A.Michael, C.Y.Kwok, "Buckling shape of elastically constrained multi-layered micro-bridges," Sensors and Actuators A: Physical, Vol.135, No.2, pp.870-880, 2007.

[67] A.Michael, C.Y.Kwok, "Design Criteria for Bi-stable Behavior of Buckled Multi-layered MEMS Bridges," J. Micromechanics and Micro engineering, Vol.16, pp. 2034-2043, 2006.

[68] Lee, C.-C., Hsiao, S.-Y., and Fang, W.: 'Implementation of a micro ball lens on a silicon optical bench using insoluble two-phase liquid immersion technology', J. Micromech. Microeng., 2010, 20, 085015 (7pp)

[69] Draheim, J., Schneider, F., Kamberger, R., Mueller, C., and Wallrabe, U.: 'Fabrication of a fluidic membrane lens system', J. Micromech. Microeng., 2009, 19, 095013 (7pp),

[70] Chang, S.-II, and Yoon J.-B.: 'A 3-D planar microlens for an effective monolithic optical interconnection system', IEEE Photonics Tech. Letters, 2006, 18, (7), pp. 814-816

[71] Shen, S. C., Pan, C. T., Liu, K. H., Chao, C. H., and Huang, J. C.: 'Fabrication of an eyeball-like spherical micro-lens array using extrusion for optical fiber coupling', $J$. Micromech. Microeng., 2009, 19, 125017 (9pp).

[72] Y W Xu, A.Michael, C.Y.Kwok, T.Puzzer, G.D.Peng, "Integration of 1D Planar Silica Grin Lenses in 3D Optical Interconnect System," Vol 48, No. 1, pp. 585-586, 2012

[73] Y.W.Xu, A.Michael, Kwok C Y, Peng G.D, “A Novel stacked die optical Interconnect Prototype system: Fabrication technique for front and rear $45^{\circ}$ micro-mirror pair", The $5^{\text {th }}$ Asia-Pacific conference on Transducers and Micro-Nano Technology, Perth, 6-9 July 2010.

[74] Y.W.Xu, A.Michael, C.Y.Kwok, G.D.Peng, “Integration of 1D planar silica GRIN lens with upward facing 45 micro-mirror", APCOT, July 2012.

[75] Y.W.Xu, A.Michael, C.Y.Kwok, T.Puzzer, G.D.Peng, “1D Planar Silica Lens Integrated 3D Optical Interconnect System - fabrication techniques of Lens Integrated Facing-down $45^{\circ}$ micro-mirror", Eurosensors XXVI, Krakow, Sept 9-12, 2012. 
